\title{
Proxy longitudinal indicators of household food insecurity in
}

\section{the UK [version 1; peer review: 1 approved]}

\author{
Neil Bernard Boyle (iD1, Maddy Power (iD)2 \\ ${ }^{1}$ School of Psychology, University of Leeds, Leeds, United Kingdom \\ ${ }^{2}$ Department of Health Sciences, University of York, UK, York, United Kingdom
}

\author{
V1 First published: 09 Aug 2021, 3:16 \\ https://doi.org/10.35241/emeraldopenres.14311.1 \\ Latest published: 09 Aug 2021, 3:16 \\ https://doi.org/10.35241/emeraldopenres.14311.1
}

\begin{abstract}
Background: Rising food bank usage in the UK suggests a growing prevalence of food insecurity. However, a formalised, representative measure of food insecurity was not collected in the UK until 2019, over a decade after the initial proliferation of food bank demand. In the absence of a direct measure of food insecurity, this article identifies and summarises longitudinal proxy indicators of UK food insecurity to gain insight into the growth of insecure access to food in the $21^{\text {st }}$ century.
\end{abstract}

Methods: A rapid evidence synthesis of academic and grey literature (2005-present) identified candidate proxy longitudinal markers of food insecurity. These were assessed to gain insight into the prevalence of, or conditions associated with, food insecurity. Results: Food bank data clearly demonstrates increased food insecurity. However, this data reflects an unrepresentative, fractional proportion of the food insecure population without accounting for $\mathrm{mild} /$ moderate insecurity, or those in need not accessing provision. Economic indicators demonstrate that a period of poor overall UK growth since 2005 has disproportionately impacted the poorest households, likely increasing vulnerability and incidence of food insecurity. This vulnerability has been exacerbated by welfare reform for some households. The COVID-19 pandemic has dramatically intensified vulnerabilities and food insecurity. Diet-related health outcomes suggest a reduction in diet quantity/quality. The causes of diet-related disease are complex and diverse; however, evidence of socio-economic inequalities in their incidence suggests poverty, and by extension, food insecurity, as key determinants.

Conclusion: Proxy measures of food insecurity suggest a significant increase since 2005, particularly for severe food insecurity. Proxy measures are inadequate to robustly assess the prevalence of food insecurity in the UK. Failure to collect standardised, representative data at the point at which food bank usage increased significantly impairs attempts to determine the full prevalence of food insecurity, understand the causes, and identify those most at risk.

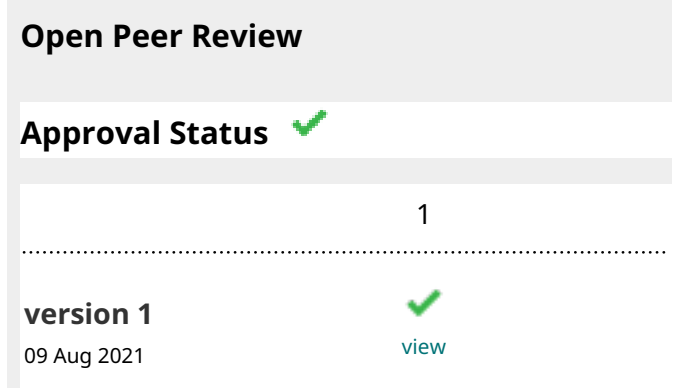

1. Amy Yau ID, London School of Hygiene \&

Tropical Medicine, London, United Kingdom Any reports and responses or comments on the article can be found at the end of the article. 
Keywords

Food insecurity, food banks, poverty, malnutrition, longitudinal data

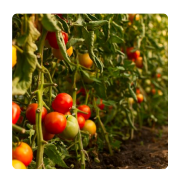

This article is included in the Sustainable Food

Systems gateway.

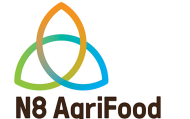

This article is included in the N8 AgriFood

N8 AgriFood collection.

Corresponding authors: Neil Bernard Boyle (n.b.boyle@leeds.ac.uk), Maddy Power (madeleine.power@york.ac.uk)

Author roles: Boyle NB: Conceptualization, Data Curation, Investigation, Methodology, Project Administration, Writing - Original Draft Preparation, Writing - Review \& Editing; Power M: Conceptualization, Data Curation, Investigation, Methodology, Project Administration, Writing - Original Draft Preparation, Writing - Review \& Editing

Competing interests: No competing interests were disclosed.

Grant information: The author(s) declared that no grants were involved in supporting this work.

Copyright: ( $\odot 2021$ Boyle NB and Power M. This is an open access article distributed under the terms of the Creative Commons Attribution License, which permits unrestricted use, distribution, and reproduction in any medium, provided the original work is properly cited.

How to cite this article: Boyle NB and Power M. Proxy longitudinal indicators of household food insecurity in the UK [version 1; peer review: 1 approved] Emerald Open Research 2021, 3:16 https://doi.org/10.35241/emeraldopenres.14311.1

First published: 09 Aug 2021, 3:16 https://doi.org/10.35241/emeraldopenres.14311.1 


\section{Introduction}

'Food security' means having access at all times to enough food that is both sufficiently varied and culturally appropriate to sustain an active and healthy life ${ }^{1}$. The Family Resource Survey (FRS) for the financial year 2019 to 2020 (data released 2021) identified $8 \%$ of UK households to be food insecure, with low household food insecurity $(4 \%)$ or very low household food security (4\%). A further $6 \%$ of the population lived in households that were marginally food secure meaning that $14 \%$ of the UK population were food insecure or marginally food insecure before the onset of COVID-192. Food insecurity was particularly high among single parent households (29\%), households in receipt of Universal Credit (UC; 43\%), Black/African/Caribbean/Black British households (19\%), and households with one or more disabled adults (19\%).

The FRS was the first large representative national survey to include questions on food insecurity providing much needed information in a field with previously limited robust data on UK household food insecurity, and no nationally representative longitudinal data. The exception to this is the Food and You Survey. From 2016, the Food Standards Agency (FSA) included the Adult Food Security Module in the bi-annual Food and You Survey. The efficacy of the survey, which covers adults living in England, Wales, and Northern Ireland, is limited by its relatively small sample size (a total of 9,319 adults from 6,408 households, compared to 19,213 households in the 2019/20 FRS). The most recent Food and You Survey (Food and You 2 - wave 1), the fieldwork for which was conducted during the COVID-19 pandemic (29 July - 6 October 2020), identified $16 \%$ of respondents to be food insecure (9\% low, $7 \%$ very low $)^{3}$. This proportion was a marked increase on previous surveys: survey Waves 4 and 5 (Food and You 1) identified $10 \%$ of households in England, Wales and Northern Ireland to be food insecure, suggesting that COVID-19 has led to sharp increases in household food insecurity (see also 4).

There has been a marked rise in the use of food banks since the 2007-08 global financial crisis suggesting rising food insecurity over the past decade ${ }^{5}$. This is corroborated by a limited number of studies, including Davis and Geiger's longitudinal analysis of the European Quality of Life Survey, which assess food insecurity utilising the single question "could your household afford a meal with meat, chicken or fish every second day if you wanted it?' ${ }^{6}$ and Loopstra, Reeves and Tarasuk's comparison of food insecurity in the 2016 Wave 4 Food and You Survey with the 2004 Low Income Diet and Nutrition Survey $^{7}$. Controlling for socioeconomic variables, Loopstra et al. found that the probability of low-income adults being food insecure rose from $27.7 \%$ (95\% CI $24.8 \%$ to $30.6 \%$ ) in 2004 to $45.8 \%$ (95\% CI $41.6 \%$ to $49.9 \%$ ) in 2016 .

Analysis of the FSA data by Loopstra, Reeves and Tarasuk suggests that, while food insecurity affects many economically deprived groups in the UK, unemployment, disability, low income and receipt of social security are characteristics specifically associated with severe food insecurity - findings corroborated by the 2019-2020 FRS data ${ }^{2}$. Indeed, it is well-established that the primary cause of food insecurity is low income and poverty, itself often attributable to social security receipt ${ }^{8}$. However poverty is not necessarily synonymous with food insecurity for example, in the United States, a high proportion of households reporting food security are poor, and a portion of households with incomes above the poverty line are food insecure .

The impacts of food insecurity on health, well-being and diet among adults are manifold and severe. Food insecurity is a cause and consequence of poor mental and physical health ${ }^{10-13}$, and associated with overweight, obesity ${ }^{14}$ and diet quality. Food insecurity also has considerable health and developmental implications for children, including lower vegetable intake and higher added sugar intake ${ }^{15,16}$ and poorer academic performance ${ }^{17}$.

In the light of the absence of longitudinal data on household food insecurity in the UK and the well-evidenced relationship between food insecurity and multiple markers of socioeconomic status, including low income ${ }^{7}$, receipt means-tested benefits ${ }^{18}$ and living in council housing/social housing ${ }^{8}$, we identify proxy indicators for food insecurity and summarise trends in these indicators since 2005 - a date which marks the start of the increase in Trussell Trust food bank usage in the UK. This article aims to provide insight into changes in poverty and nutritional deficiencies since 2005 as an indication of possible trends in food insecurity in the twenty-first century.

The study had two main aims:

1. To conduct a rapid evidence review to identify candidate proxy indicators of household food insecurity in the UK.

2. To collate and present evidence from the identified indicators in an attempt to ascertain if it is possible to appraise the prevalence of household food insecurity in the UK over the last 15 years.

\section{Methods}

The absence of a direct measure of UK food insecurity necessitates the use of proxy or ancillary markers that may give an approximate indication of the prevalence of food insecurity or, more accurately, the prevalence of the conditions that may be associated with or increase the likelihood of food insecurity. To identify potential markers that could be used to approximate the level or prevalence of historical food insecurity in the UK, we conducted a rapid evidence review of the existing literature. A systematic search of peer-reviewed articles and grey resources was undertaken by the authors. The criteria for inclusion were as follows: a) conditions of interest: any published works or grey literature that report direct or proxy indicators of food insecurity in the UK published between January 2005 and the present day; b) outcomes of interest: any indicator that directly measures food insecurity or any proxy indicator that is associated with food insecurity or the conditions which increase the likelihood of food insecurity; c) setting: United Kingdom only; d) study designs: all study designs; e) article published in the English language; and f) full text available. 
Searches were conducted by both authors between March 2020 and May 2020. Full text database searches (inclusive of records 2005-2020) of Web of Science, PsycINFO, and EMBASE were conducted in April 2020. The following search terms were used: 'food insecurity AND indicator*'; 'food poverty AND indicator*'; 'food poverty AND Measur*'; 'Food insecurity AND Measur*'. Additional filters of 'UK', 'United Kingdom', England, Wales, Scotland, Northern Ireland, and NI were applied to the search findings. Results from the first 50 pages of a GoogleScholar 'anywhere in text' search for 'food insecurity indicator UK' were also reviewed. The authors' own experience in the area of food insecurity and consultation with contacts working in food insecurity sector further informed the selection of markers to include. Government statistics and reports were also searched to identify data relevant to the study aims to be included in the review.

The initial database searches returned a total of 5,164 publications. This was reduced to 69 publications after geographical filters were applied. Publication titles were reviewed to remove patently irrelevant and duplicate publications, leaving a total of 39 articles selected for abstract review. The full text versions of 36 publications were retrieved and examined. Articles were reviewed by the authors and those that did not meet the criteria were excluded by consensus. Based on the articles, grey literature and governmental data sources retrieved through the search, potential indicators were extracted from source. The indicators were listed with methods to extract data for each indicator (e.g. ONS), and the source from which the indicator was taken (e.g. published work or charity report). Both reviewers agreed on the most relevant indicators of food insecurity based on the relevance of the indicator and availability of longitudinal data.

\section{Results}

The multiple proxy indicators for food insecurity we identified included: use of food banks; economic markers showing general economic trends; household income; measures of income-related poverty; changes in social security; benefit sanctions and conditionality; housing costs; the costs of food; and trends in malnutrition and dietary markers. The following sections discuss each of these proxy indicators in turn, explaining the rationale for their inclusion and setting out longitudinal data on trends.

\section{Food banks}

In the absence of any direct measure of food insecurity in the UK there has been reliance on estimates of food bank usage, predominantly Trussell Trust food banks, to monitor the changing prevalence of food insecurity over time. The Trussell Trust has published data on the growth of their network and scale of provision since $2005^{19}$ (see Figure 1).

The number of Trussell Trust food banks, as well as the number of food parcels distributed, increased significantly from 2011/2012. These increases are echoed in data collated by independent food aid providers ${ }^{20}$. In early 2021, there were an estimated 1,300 Trussell Trust and over 1052 independent food banks operating in the UK. The COVID-19 pandemic has further accelerated the number of food aid providers and distribution of food parcels. By the end of April 2020, the Trussell Trust reported an $89 \%$ increase in food parcel distribution compared to April 201921; the Independent Food Aid Network (IFAN) reported an increase of emergency food parcel distribution of $175 \%$ between the same comparison periods ${ }^{21}$.

These data certainly suggest a growth in food insecurity since 2005. However, it is increasingly acknowledged that using food bank data to estimate objective levels of food insecurity is problematic. The number of operating food banks is a poor objective indicator of food insecurity since the creation of a food bank is reliant on and driven by action of local community partners. Whilst this is likely driven by local need, there will be incidences where there is a local need for provision but a lack of local networks to establish a food bank. Further, the number of food parcels distributed has until
A

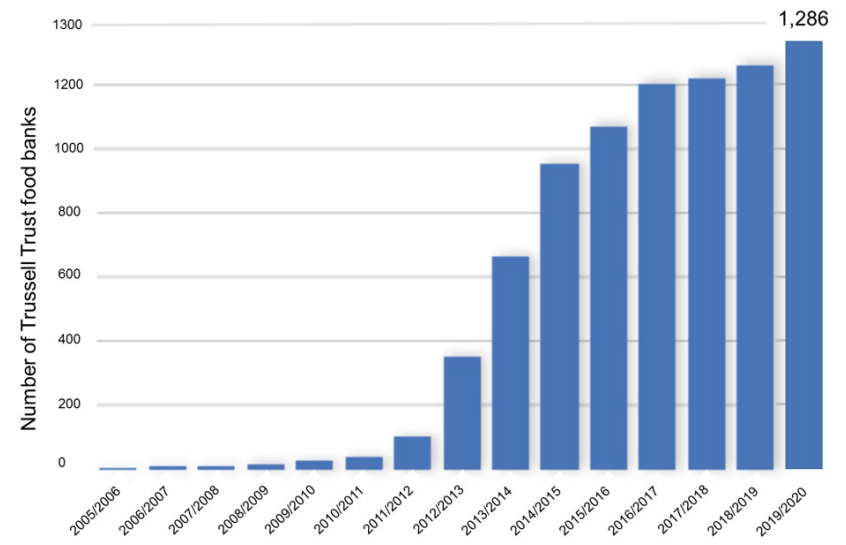

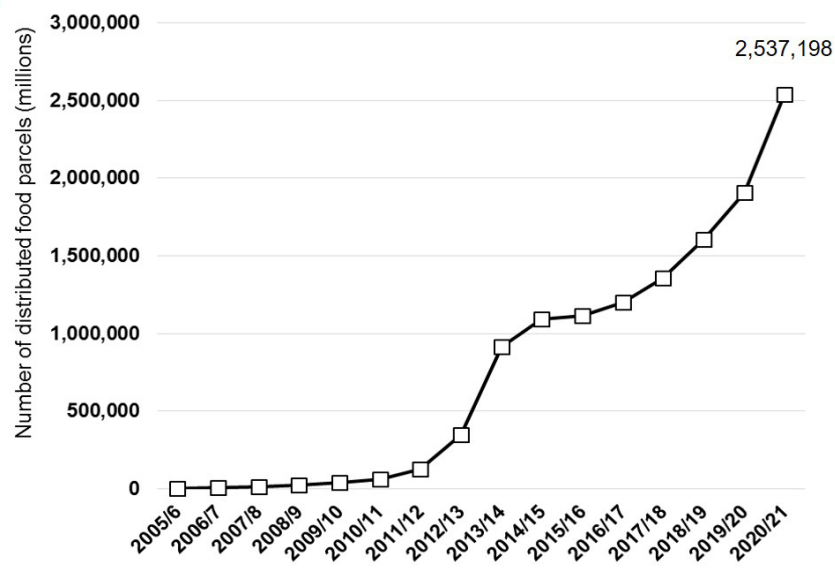

Figure 1. A. Number of food banks in the Trussell Trust network 2005/06 - 2019/20. B. Number of Trussell Trust food parcel distributed in the UK 2005/06 - 2020/21. Data from Trussell Trust data: http://www.trusselltrust.org/wp-content/uploads/sites/2/2015/06/BIGGEST-EVERINCREASE-IN-UK-FOODBANK-USE.pdf; https://www.trusselltrust.org/state-of-hunger/. 
recently been indicative of the total volume of parcels allocated rather than the number of distinct individuals receiving food aid. The Trussell Trust started recording unique food bank users in April 2016, but this data offers an incomplete picture of the prevalence of food insecurity. It is often unclear how many distinct households are accessing food bank parcels and, moreover, the majority of those who are food insecure may not seek food aid provision. In Canada, it has been estimated that only $20 \%$ of food insecure individuals access food banks $^{22}$, findings echoed by recent UK evidence ${ }^{23}$. The vast majority of those accessing food aid in the UK are considered destitute $^{19}$ and likely representative of individuals facing severe food insecurity. Therefore food bank data can be considered to be indicative of a non-representative subset of the food insecure population ${ }^{22}$.

\section{Economic markers}

Macroeconomic markers are likely to blunt a measure to give any granular insight into the potential indicators or prevalence of food insecurity, since general economic trends may obscure the micro economic factors that may impact specific sections of the population. However, a wider perspective on the general economic landscape since 2005 serves as a useful background against which to discuss more detailed and specific proxy markers associated with food insecurity risk. Since 2005, the UK economy has been characterised by relatively low levels of economic growth ${ }^{24,25}$. The 2007-2008 Great Recession (hereafter the 'recession') instigated a significant downturn in growth between the years 2008 and 2013, a period which witnessed a marked upsurge in food bank usage. Unemployment also increased significantly during the recession years (and economic fallout) of 2008-2013 (Figure 2). Since this period, UK employment rates have steadily grown to levels above those reported pre-recession.

In the following sections, we consider historical data on the absolute and relative income of the UK population and how this relates to the cost of living and capacity to acquire food of sufficient quantity and quality over time. In the wake of the recession, the Coalition and Conservative governments instigated a long period of economic austerity and welfare retrenchment characterised by significant public spending cuts. Therefore, it is essential to examine historical data in relation to public spending and benefits to illustrate the changing public spending landscape that may have contributed to food insecurity vulnerability. The identification of proxy markers of food insecurity was undertaken at the start of the COVID-19 outbreak before the profound economic and social impacts of the pandemic were fully appreciated. Unsurprisingly, early reports were suggestive of catastrophic effects of the pandemic on the prevalence of food insecurity. The recession, often cited as the key catalyst for the growth in food insecurity, resulted in a maximal single quarter shrinkage in the UK economy of $2.1 \%$. The UK economy shrank $3 \%$ in the first quarter of 2020 as COVID-19 lockdown restrictions were introduced; by the second quarter of 2020 this shrinkage had risen to a historically unprecedented $18.8 \%$ (see Figure $3^{24}$ ).

\section{Household income}

The capacity to afford sufficient and appropriate food to sustain an active and healthy life is intrinsically linked to household income. Figure 4 shows the median net household income between 2005 and 2018 for the UK population. Median income represents the level of household income above $50 \%$ of the UK population as a whole, giving an indication of average living standards of a population. Income is measured at the household level after the deduction of taxes and addition of state benefits and tax credits. Income is then 'equivalised' to rescale the value to account for different needs of households of different sizes and compositions. The median income can be calculated before housing $\operatorname{costs}^{1}$ (BHC) or after housing costs (AHC) are deducted from income.

${ }^{1}$ Housing costs are inclusive of rent (gross of housing benefit), water rates (including council and community charges), mortgage interest payments and structural insurance premiums (for owner occupiers) and ground rent and service charges.
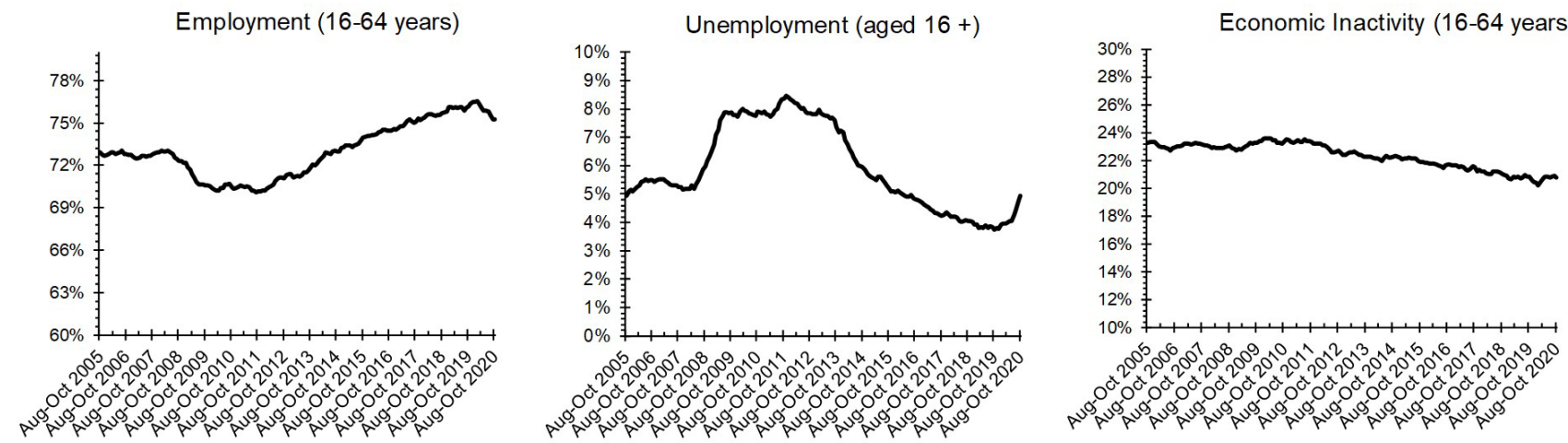

Employment includes both those who are in work during the reference period and those who are temporarily away from a job including maternity/paternity and annual leave and furloughed workers. Unemployment refers to those without current employment but actively seeking and ready to commence work within 2 weeks. Economic inactivity refers to those without a job but not classed as unemployed due to not actively seeking work or ready to commence work

Figure 2. UK Employment, unemployment and economic inactivity levels (\%) Aug-Oct 2005 - Aug-Oct 2020. Data from Office for National Statistics Labour Force Survey: https://www.ons.gov.uk/employmentandlabourmarket/peopleinwork/ employmentandemployeetypes/bulletins/uklabourmarket/january2021. 


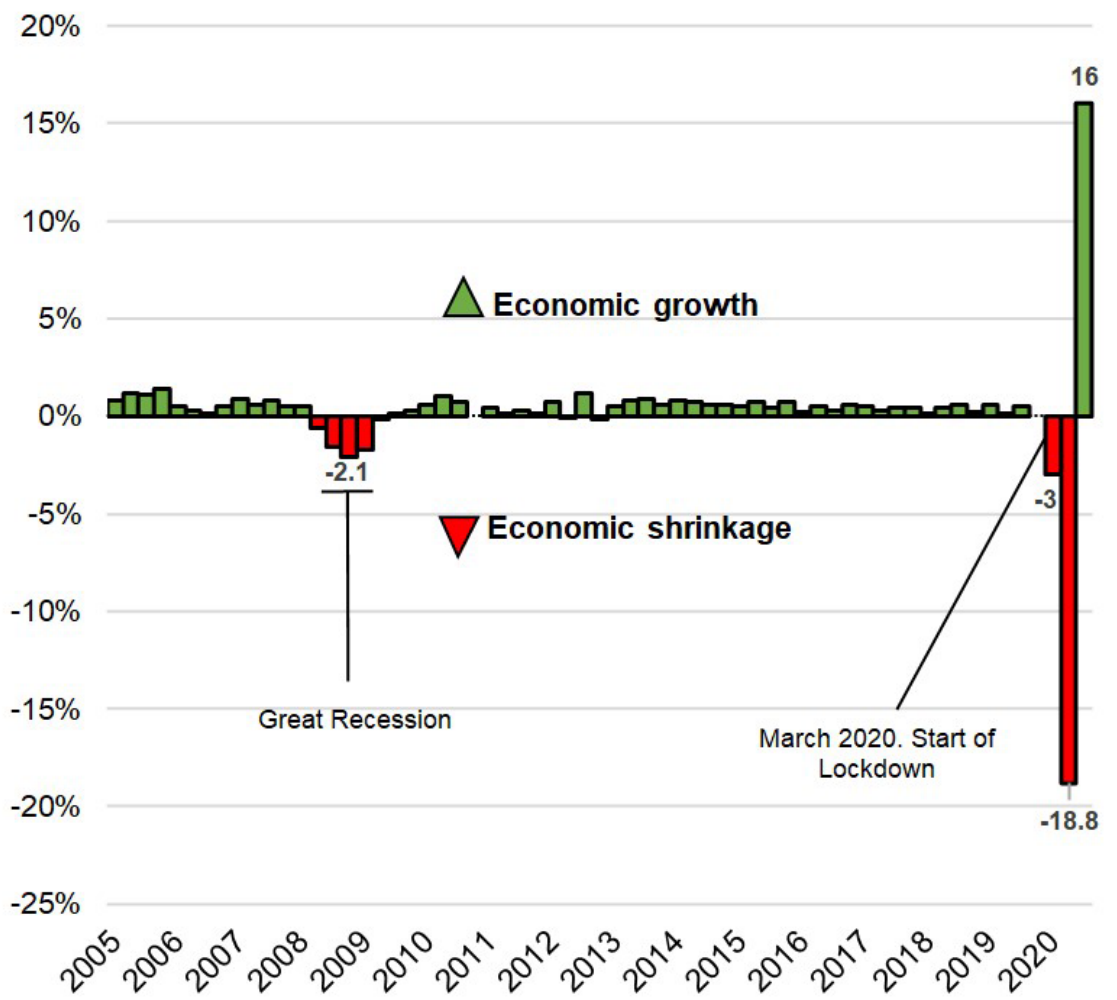

Figure 3. UK GDP growth, Quarter 1 (Jan to Mar) 2005 until Quarter 3 (July to September) 2020. Data from: Office for National Statistics. https://www.ons.gov.uk/economy/grossdomesticproductgdp/timeseries/ihyq/qna.

By historical standards, recent median income growth in the UK has been characterised by a prolonged period of dismal growth resulting in over a decade of unprecedented limited improvement in average living standards ${ }^{26}$. An average year on year increase of just $0.3 \%$ in income $\mathrm{BHC}$ was recorded between 2008-2018; the slowest growth over any 10 year period since the $1970 \mathrm{~s}^{26}$. After a slump during the recession, some growth in median income was evident between 2015-2017. However, the impact of Brexit on the rate of inflation and depreciation of the Sterling contributed to the stalling of income growth from 2017 onwards. Prior to the COVID-19 pandemic, growth was forecast to slow even further as the full economic effects of the UK leaving the EU unfurled. The impact of COVID-19 on average income has yet to be fully appreciated; however, prior to lockdown restrictions, UK median BHC income had not increased since 2015 and had grown only $4 \%$ compared to average income on the eve of the recession in 2008. It is highly likely the ongoing impact of COVID-19 will further depress the median UK income for some time.

\section{Demographic inequality in household income}

It is important to further interrogate data on median average income by demographic variables to ascertain if specific sections of the UK population have experienced comparable income profiles over time. Figure 4 also shows the median income for those aged below and above 60 years. Those over 60 years have experienced a more consistently rising median income since 2005, both BHC and AHC. The relative difference in median income between the age groups largely disappears AHC, which reflects a higher percentage of those over 60 owning their own homes. In 2018 the median income in the over 60's was $12 \%$ higher than prior to the recession in 2007; growth was $3 \%$ during the same period for those below 60 years ${ }^{26}$. However, growth has stalled for all age groups since 2017. This age disparity in average income growth corresponds to demographic food bank usage data that shows the greatest risk of being referred to food banks in those aged 25-54, with those of pension age $(65+$ years $)$ comprising a minority of referrals $(2 \%)^{19}$. This is further supported by data from the FRS food insecurity module that reported $3 \%$ of $64-74$ year olds and $1 \%$ of those 74 years and above lived in food insecure households in 2019-20; compared to a range of $8-15 \%$ of those in younger age groups ${ }^{2}$. However, the reported weekly equivalised household income AHC of Trussell Trust food bank users in 2018 was in the region of $£ 50^{19}$. It is, thus, evident, that there is considerable variability in income around the median household 


\section{UK Median Net Household Income}

Before Housing Costs

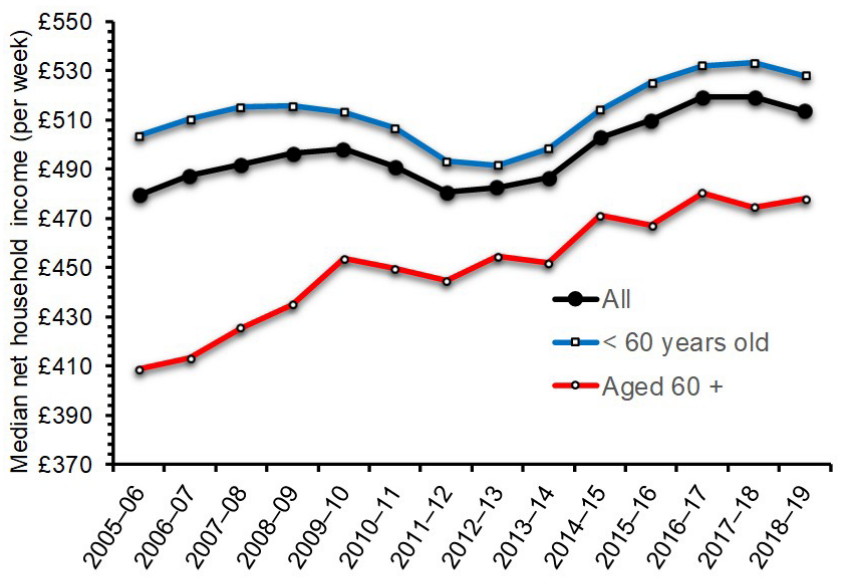

After Housing Costs

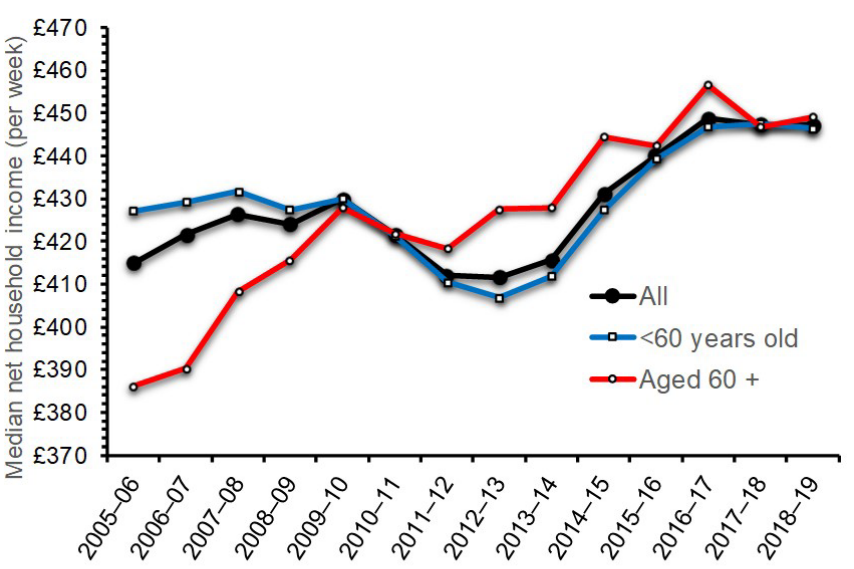

Data from Family Resources Survey. Incomes have been measured net of taxes and benefits before and after housing costs have been deducted and are expressed in 2018-19 prices. All incomes have been equivalised using the modified OECD equivalence scale and are expressed in terms of equivalent amounts for a childless couple

Figure 4. UK median net household income (before and after housing costs) 2005/06 - 2018/19, overall and by age group. Adapted with Institute for Fiscal Studies permission from Bourquin et al., 2020. Living standards, poverty and inequality in the UK: 2020. IFS: https://www.ifs.org.uk/uploads/R170-Living-standards-poverty-and-inequality-in-the-UK-2019-2020\%20.pdf.

income. Examination of incomes along the distribution will provide a clearer indication of the relative risk of having insufficient income to afford an adequate diet.

\section{Economic inequality in household income growth}

Figure 5 shows the real income growth in percentile of household income BHC and AHC. Analysis by Bourquin et al. ${ }^{26}$ found that BHC incomes in 2018 were comparable to those in 2015 for the $50^{\text {th }}, 25^{\text {th }}$ and $75^{\text {th }}$ percentiles. At the lower end of the distribution, a markedly slower growth in income is shown in the $10^{\text {th }}$ percentile of incomes with a lack of overall growth since 2013. This compares to a $6 \%$ growth in income in the $90^{\text {th }}$ percentile since 2013 . The fall in income growth since 2016 in the $10^{\text {th }}$ percentile is even more pronounced after housing costs have been deducted (see Figure 5). Overall, the lowest income households have seen little change in living standards since 2013 as a result of reduced income levels since 2016, essentially eradicating any income gains between 2013 and 2020 .

To understand the comparative lack of income growth since 2013 in the lowest income households Bourquin et al. identified the different sources from which households across the BHC income distribution typically derived income. Findings suggest income gains made by low-income households as a result of rising employment during 2013-2016 were largely offset by a $7 \%$ fall in the real value of working-age benefits and tax credits. This was further compounded by the stagnation in income growth across the UK in 2016 as a result of rises in inflation $^{26}$. Overall, it is estimated that reduced income from working-age benefits and tax credits since 2013 contributed to an $8 \%$ reduction in income in the lowest income households. This essentially mitigated the effects of increased income from rising employment (estimated to be a $9 \%$ net increase in income during this period ${ }^{26}$ ).

\section{Measures of income-related poverty}

Measures of poverty are commonly based upon the determination of income available to a household. The UK government measures poverty in relation to median household income. A distinction is made between the 'absolute' poverty rate, which compares household income to a median income level fixed in time (a base median income year of 2010-11 is used for the Department of Work and Pension's [DWP] Households Below Average Income [HBAI] statistics), and 'relative' poverty rate which compares household income to the median household income in the same year. A threshold of $60 \%$ below the comparison median household income value is adopted to characterise households falling into absolute and relative poverty. HBAI statistics assume all individuals in the household benefit equally from the combined household income and this is net of taxes and benefits and equivalised based on household size and composition.

Relative poverty rates give an indication of whether the poorest households are keeping up with the households in the middle of the distribution and are considered more informative when looking at data over longer periods since the notion 


\section{Real growth in percentiles of household income}

\section{Before Housing Costs}

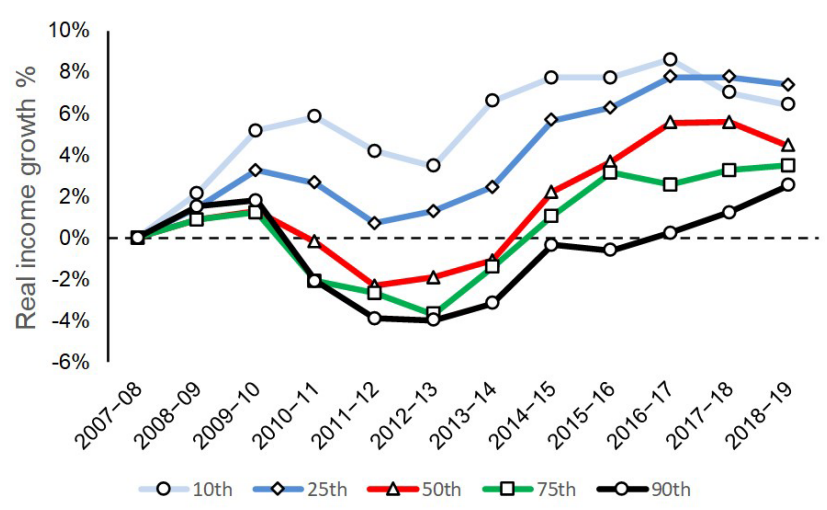

After Housing Costs

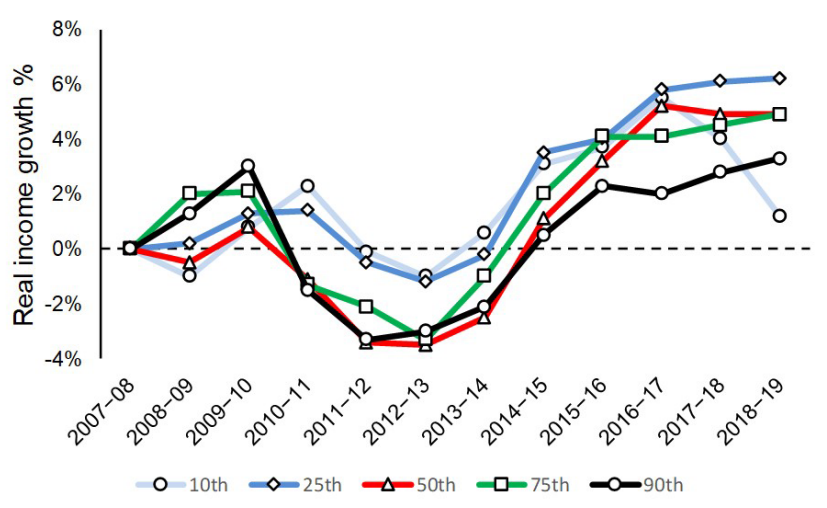

Data from Family Resources Survey. Incomes were measured net of taxes and benefits before (left) and after (right) housing costs have been deducted and have been equivalised using the modified OECD equivalence scale.

Figure 5. Real growth in percentiles of household income BHC and AHC 2007/08-2018/19. Adapted with Institute for Fiscal Studies permission from Bourquin et al., 2020. Living standards, poverty and inequality in the UK: 2020. IFS: https://www.ifs.org.uk/uploads/R170Living-standards-poverty-and-inequality-in-the-UK-2019-2020\%20.pdf.

of an 'acceptable standard of living' is likely to be relative and to change over time. Absolute poverty rates are considered to reflect the real income of the poorest households irrespective of trends across other households and are more informative over shorter time periods ${ }^{27}$. Both measures of poverty rate are calculated BHC and AHC. The DWP recommends the use of BHC when assessing the poverty rates for children and working age adults as AHC may underestimate the living standards of those who spend a larger proportion of their income on housing, either due to the unaffordability of local housing stock or the desire to attain a higher standard of living. However, AHC will be considered for all demographic groups here since poorer households tend to spend a higher proportion of their income on housing ${ }^{28}$, and this disparity between the poorest and wealthiest households has increased over recent years ${ }^{29}$. BHC income is also sensitive to fluctuations in Housing Benefit as rent costs increase or decrease, which gives the false impression of a rise or fall in income without any change in standard of living in the household ${ }^{27}$.

Figure 6 shows the equivalised relative UK poverty (AHC) in the population as a whole and by demographic group between 2005 and 2018. It is important to note there is a significant lag in the reporting of UK poverty data. At the time of writing, data is only available up to 2018. In the UK population as a whole, the relative poverty rate has remained stable around $22 \%$ since 2005. A decline in child and pensioner AHC relative poverty resulted in a small drop in overall UK poverty rates between 2007 and 2011 (22.5\% to $21 \%$ ). This reflects the incomes of poorer households increasing faster than the median household income after a fall in real earnings and increase in real benefit receipt in the wake of the 2008 recession. As discussed previously, this was essentially mitigated from 2008 and particularly from 2010 as median incomes increased and working age benefits value decreased ${ }^{27,30}$. By 2018, relative poverty rates had roughly returned to levels recorded before the onset of the 2008 recession. However, the different demographic groups saw contrasting poverty rate profiles in the intervening years. Working-age adults without children have seen reduced poverty rates since 2011 (19.4\% to $15.8 \%)$. A sustained increase in child poverty is seen from 2011, increasing from $\sim 27 \%$ and stabilising at around $30 \%$ from 2016 onwards; the most sustained rise in relative child poverty since early 1990 . Pensioner poverty has almost halved since the 1990s and showed signs of continued improvement during the recession, largely due to government policy decisions. Increases have been recorded since 2014 - although some question if this represents a genuine trend $^{31}$.

Children are the most likely group to experience poverty. A 2017 analysis by the Institute of Fiscal Studies (IFS) projected poverty rates in pensioners and working-age adults without children to remain largely unchanged up to 2021. Conversely, childhood poverty was projected to significantly increase from $29.7 \%$ in 2015 to $36.6 \%$ by $2021^{27}$. Children are more likely to experience relative poverty due to poorer households with children tending to obtain less of their household income directly from earnings ${ }^{32}$. Therefore, as real earnings grow, those that receive more of their income from earnings - e.g. working-age adults without children - are more likely to see their incomes increase in line with real income growth. Pensioners are similarly protected since the state pension and pension credits are 'triple locked' linked to the highest marker of income growth (average earnings, CPI inflation or 2.5\%). Poorer households receiving more of their income from social security are vulnerable to fluctuations in social welfare value 


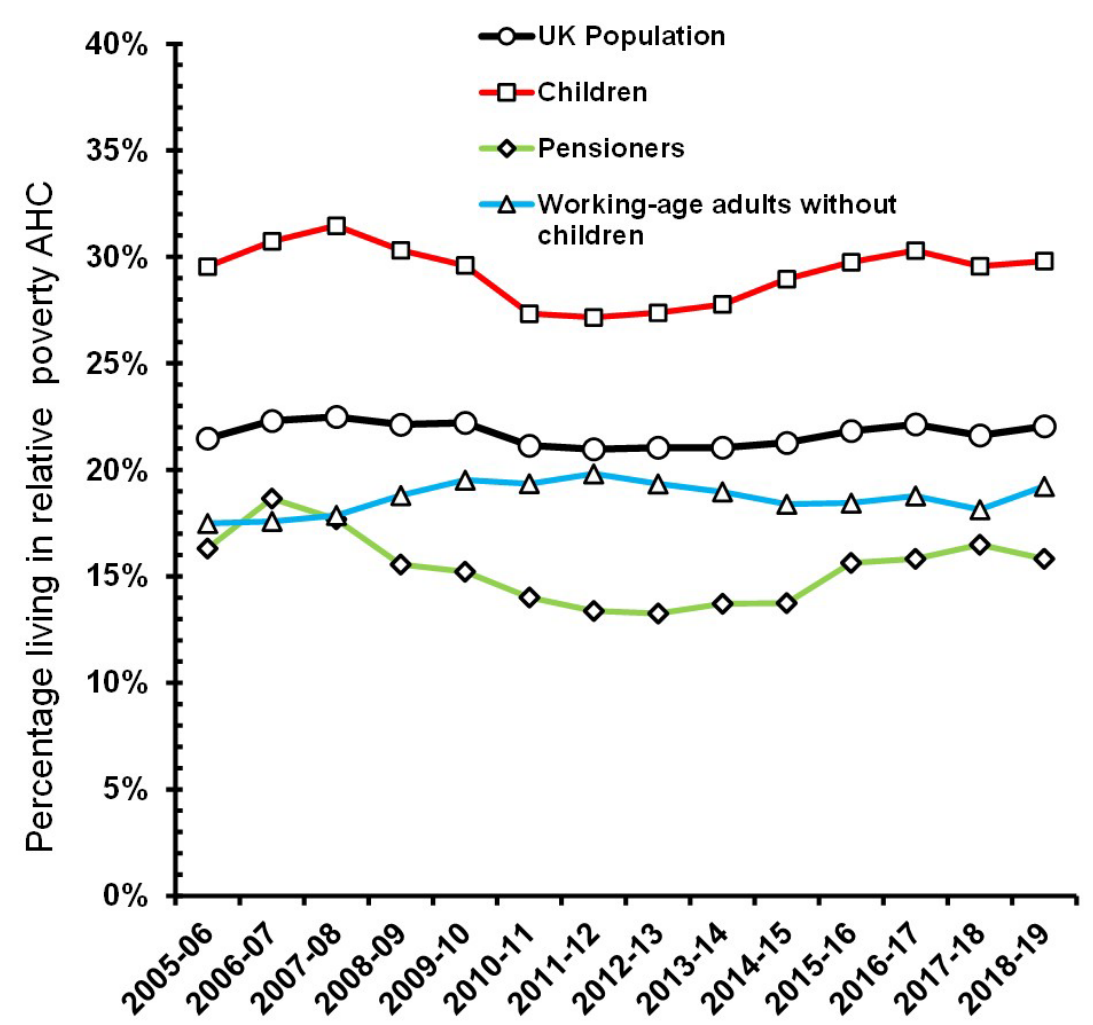

Data from Family Resources Survey. Equivalised household income less than $60 \%$ of the median income in reported year.

Figure 6. Relative UK poverty rate (AHC) by population and demographic group 2005/06 - 2018/19. Adapted with Institute for Fiscal Studies permission from Bourquin et al., 2020. Living standards, poverty and inequality in the UK: 2020. IFS: https://www.ifs.org.uk/uploads/ R170-Living-standards-poverty-and-inequality-in-the-UK-2019-2020\%20.pdf.

or changes to benefit entitlements ${ }^{27}$. For example, the introduction of the 'two-child limit' effectively removed any tax or UC contribution for any third and additional children born on or after the 6th April 2017. This is likely to significantly reduce the income of poorer households and increase the risk of being driven into relative poverty.

Figure 7 shows the equivalised absolute UK poverty (AHC) in the population as a whole and by demographic group between 2007 and 2018. A modest $2.1 \%$ fall in absolute poverty rates was seen between 2007-2015, largely driven by favourable social security policies reducing child and pensioner poverty ${ }^{27}$. However, the reduction in absolute poverty rates in the UK over recent years has been small by historical standards. Absolute poverty was reduced by $1.4 \%$ between 2010 - 2018. An average reduction of $5-6 \%$ has been reported in recent decades over the equivalent time period. There has been very little change in absolute poverty rates since 2016. This appears contradictory since low-income households have seen a reduction in earnings during this period (see Figure 5). As Bourquin et al. ${ }^{26}$ emphasise, this has not been accompanied by a subsequent reduction in the absolute poverty rate as falls in income during this period were isolated to those households below the poverty line. In fact, falls in incomes since 2016 were seen only in the $10^{\text {th }}$ percentile of the distribution, representing a deepening of poverty in those already most vulnerable to its impact.

Alternative poverty metrics are available which include additional social and resource-based measures, but these tend to be less suitable for comparing trends over longer periods of time. For example, low income and material deprivation measures combine a low income threshold (the DWP employs $70 \%$ below median income) with an assessment of household material deprivation, i.e. capacity to access key goods or services. However, the indicators used to determine deprivation since 2005 have varied so are not suitable for assessing changes over the whole time period. Recent data estimate that $11 \%$ of children in the UK were in low income and material deprivation in 2018. This represents a fall against comparable data that estimated a prevalence of roughly $13 \%$ between $2010-2014^{28}$. This may be as a result of price falls in some material items relied on more in low-income households ${ }^{19}$. Data prior to these years are based on non-equivalent metrics.

Estimates of poverty are influenced by a number of potential confounding factors, which may serve to inflate or underestimate 


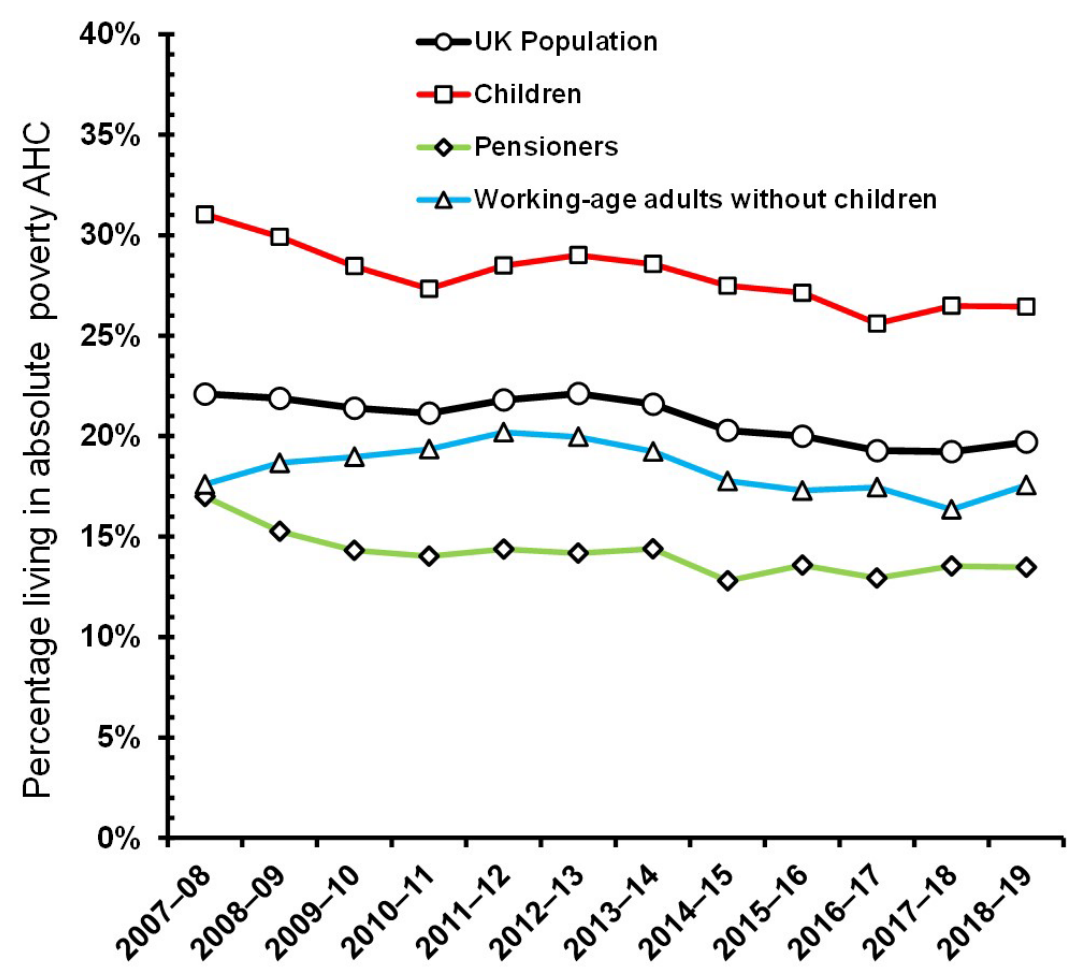

Data from Family Resources Survey. Equivalised household income less than $60 \%$ of median AHC income in 2010-11.

Figure 7. Absolute UK poverty rate (AHC) by population and demographic groups 2007/08 $\mathbf{- 2 0 1 8 / 1 9}$. Adapted with Institute for Fiscal Studies permission from Bourquin et al., 2020. Living standards, poverty and inequality in the UK: 2020. IFS: https://www.ifs.org.uk/ uploads/R170-Living-standards-poverty-and-inequality-in-the-UK-2019-2020\%20.pdf.

the true level of poverty. Data on UK poverty are taken from the FRS that employs responses from $\sim 19,000$ households each year to estimate the distribution of income. However, it is clear that a level of under-reporting occurs, particularly in relation to the receipt of social security since there is often a disparity between the reported benefits received and government benefit expenditure ${ }^{28}$. Conversely, the use of a cross-sectional survey to estimate poverty levels fails to acknowledge that poverty is not static and would not account for those households that may fall in and out of poverty on multiple occasions over the year; therefore underestimation of poverty levels is also possible. Data on persistent levels of poverty - defined as experiencing relative low income for at least 3 of the last 4 years - suggest $13 \%$ of the UK population experienced persistent low-income (AHC) between 2014 - 2018; children were again the most affected by persistent poverty in the UK (based on Understanding Society survey ${ }^{28}$ ).

In-work poverty

Having a job doesn't necessarily secure an adequate standard of living or protect households from poverty and food insecurity.
Despite rising employment rates prior to the pandemic and the introduction of the National Living Wage, 58\% of working households - households with at least one adult in paid employment - were living below the UK relative poverty line in 2017/18; compared to $37 \%$ of working households in $1994 / 95^{29}$. This heightened proportion of in poverty working households is largely reflective of changes in the labour market. Reduced household worklessness has increased the number of typically low-earning households in work (e.g. lone parents) which has changed the composition of working households. Improvements in the living standards of pensioners and workless households has also pushed up the relative poverty line. However, a third of the increase in working poverty is as a result of a rise in relative poverty for working households ${ }^{29}$. This in-work poverty rate has increased from $\sim 14 \%$ in $2004 / 5$ to $18.2 \%$ in $2018 / 19$, an increase of over $30 \%{ }^{29}$. Children may be particularly impacted by rising in-work poverty trends with an estimated seven in ten children in poverty living in a working household in 2019/2033. Analysis by Bourquin et al. ${ }^{29}$ suggests that increased in-work poverty was a result of: (i) increased disparity in proportional household earnings growth (pre-tax total household 
income) between low and higher income households, and (ii) a disproportionate rise in housing costs for low vs higher income households.

A rising number of those in employment find themselves in jobs with little security. The emergence in the labour market of the 'precariat' - those employed in temporary and zero-hour contracts - has been a subject of much debate since such nonstandard forms ${ }^{2}$ of working expanded. Figure 8 shows the proportion of UK adults employed on zero-hour contracts between 2005 and 2020. Whilst the number of zero-hour contracts have been rising since 2005, a noticeable increase is evident after the recession from 2013. Increases in zero-hour contracts have been particularly concentrated in younger adults, constituting $8.8 \%$ of employment in 16-24 year olds in $2019^{34}$. The UK government has suggested zero-contracts represent part of a growing employment flexibility in the UK labour market ${ }^{35}$. However, as zero-hour jobs are concentrated in low-paid low-skill

${ }^{2}$ Non-standard is defined by the International Labour Organization (ILO) as any form of employment that deviates from standard employment, which consists of guaranteed minimum employment standards and security of tenure. jobs and often characterised by inconsistent, unguaranteed hours, they are inevitably associated with precarious income. Table 1 shows the proportion of zero-hour contract workers satisfied with the level of employment they could access in 2020. Whilst there is support for the government's assertion that zero-hour contracts give many individuals a desired flexibility in working pattern $(61 \%$ indicating they did not want more hours), 29\% reported underemployment ${ }^{34}$. People in poverty are much more likely to be underemployed ${ }^{33}$. Further, a 2019 review of independent food banks in England reported $62 \%$ of those accessing food parcels were employed on zero-hour contracts. Therefore, the increase in such precarious types of employment over recent years has likely contributed to some degree to heightened vulnerability to food insecurity for some. Those working on zero-hour contracts also have less employment benefits such as redundancy rights and pension contributions. Precarious working is also associated with increased stress and greater incidence of impaired mental and physical health ${ }^{36}$. These additional factors may further increase vulnerability to poverty and food insecurity.

The economic impact of the pandemic has been largely concentrated in industries characterised by zero-hour working practices: wholesale and retail, accommodation and food services, and health and social work services. The primary affected

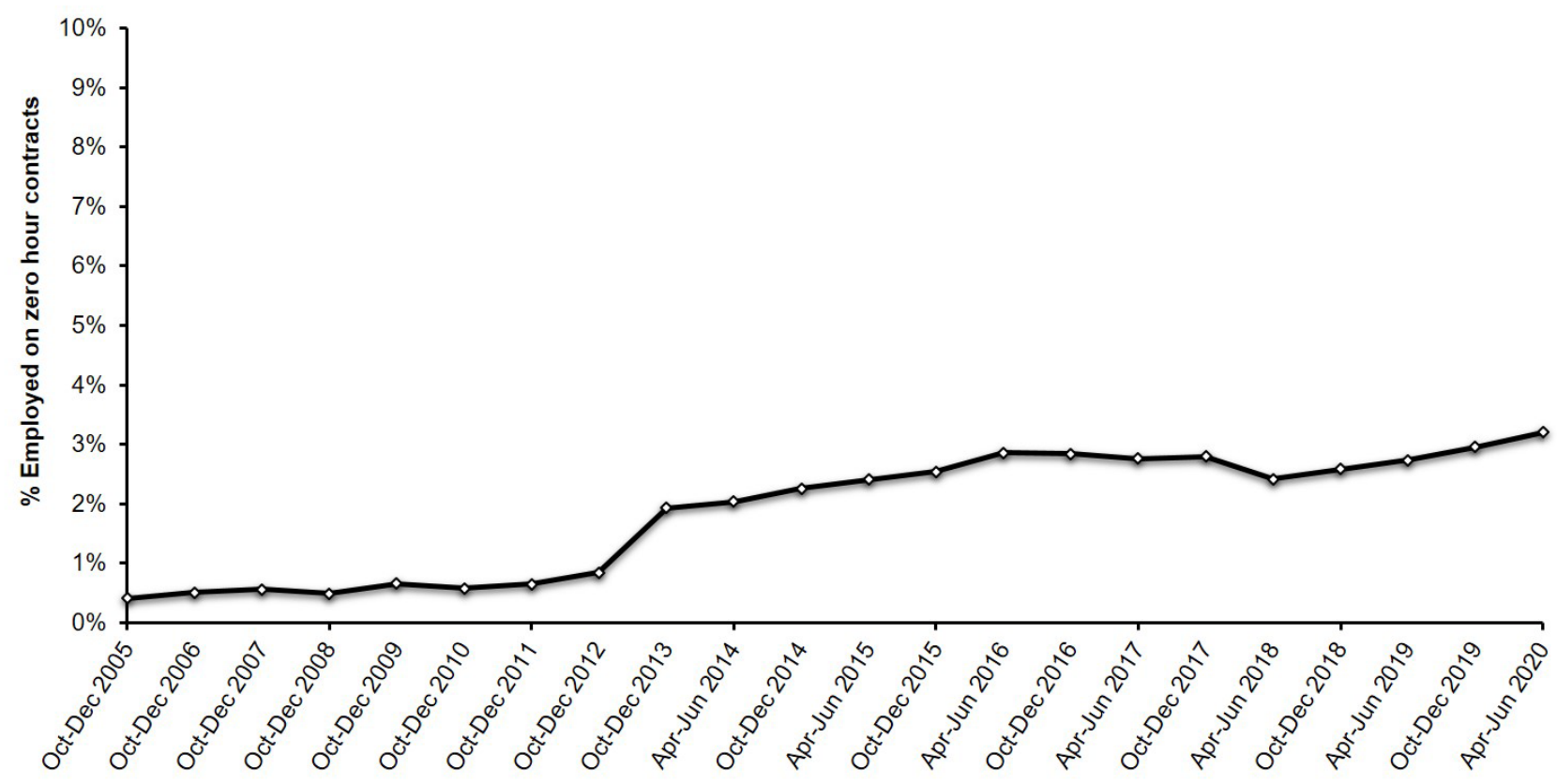

Data are not seasonally adjusted

Figure 8. Proportionate of UK adults in employment on zero hour contracts 2005 - 2020. Data from ONS Labour Force Survey: https://www.ons.gov.uk/employmentandlabourmarket/peopleinwork/employmentandemployeetypes/datasets/ emp17peopleinemploymentonzerohourscontracts. 
Table 1. Responses of workers (16+ years) on zero-hours contracts April to June 2020 (EMP17: Looking for more hours).

\begin{tabular}{|c|l|}
\hline \begin{tabular}{|l|l|} 
Wants additional job \\
Wants replacement job with longer hours
\end{tabular} & $\begin{array}{l}\text { \% of people } \\
\text { on a zero- } \\
\text { hour contract }\end{array}$ \\
\hline Wants more hours in current job & 4.3 \\
\hline Total underemployed & 21.4 \\
\hline Does not want more hours & 29.2 \\
\hline Unknown status & 61.0 \\
\hline
\end{tabular}

jobs are also low income and not suited to home working. Lockdown greatly increased underemployment in these sectors, which is expected to translate to unemployment as government support schemes are withdraw ${ }^{37}$. This is likely to further increase the risk of those in low-paid, non-standard (e.g. zero-hour contracts) employment facing increased vulnerability to food insecurity.

\section{Social security}

Changes to the UK social security system have clear implications for households most vulnerable to experiencing food insecurity since a higher proportion of income in poorer households is derived from social security. This was firmly supported by the 2019/20 FRS food insecurity module in which $43 \%$ of households in receipt of UC reported low or very low food security ${ }^{2}$. A primary function of the social security system is to replace or supplement incomes to permit individuals and households to meet the fundamental costs of living if they are unable to adequately do so through employment. Means tested benefits - such as UC, Jobseeker's Allowance (JSA), Working Tax Credit, and Housing Benefit - are allocated based on relative need (e.g. size of family) to protect a basic standard of living for recipients. To ensure social security benefits are sufficient to permit those they support to afford the costs of living, benefits have traditionally been reviewed on an annual basis. Since the 1980's, benefit entitlements have been uprated in line with the relative costs of living and yearly inflation rate; from 2005 up to 2012 this averaged approximately $2 \%$ each year ${ }^{33}$. In the wake of the recession, the UK Conservative-led Coalition and subsequent Conservative governments implemented sweeping welfare reforms under the banner of austerity. Benefit uprating was limited to a $1 \%$ yearly increase between 20122016. Since 2016 - with some exceptions such as 'triple-locked' state pension entitlements - benefits have been subject to a 'benefits freeze', essentially cancelling the uprating of benefits in line with inflation ${ }^{33}$. Freezing enhancements resulted in the value of benefits being vulnerable to changes in the inflation rate.

Data presented in the Joseph Rowntree Foundation 2020 report $^{38}$ on UK poverty highlights increases in inflation after a post-recession slump reduced the real value of benefits since 2016 placing severe constraints on low-income household budgets. Figure 9 shows the real value of UK benefits fell $6 \%$ between 2013-2019 ${ }^{33}$. This loss of 'real value' essentially means a reduced capacity to afford the costs of living if the price of essential items - such as food - increase over time. As outlined below, food prices did increase significantly during the recession and subsequent recovery period, which feasibly could have contributed to increased vulnerability to food insecurity.

Child benefit payments have been subject to a longer uprating freeze, having been frozen between 2010-2014 and subsequently at 2015 rates until April 2020 (see Figure 10). Benefits to support families have been further impacted by the 'two-child limit' policy. The effects of this policy have been slow to materialise but by April 2020 the two-child limit policy affected 911,000 children $^{39}$. This policy affects in-work as well as out-of-work benefits, primarily impacting the unemployed and those in low-paid employment. Indeed, the majority of affected households in $2020(57 \%)$ were classified as in-work ${ }^{39}$. These are unprecedented changes to support given to families in Europe. The two-child policy is predicted to have a growing impact on household poverty. Affected families could lose up to $£ 2,780$ per annum for every child beyond the second ${ }^{27}$. The policy also specifically reduces the income of larger households that are already more vulnerable to being in, or close to falling into, poverty. Considering children are already much more likely to experience poverty, such policies must be considered as potentially contributing to an increased risk of food insecurity.

Uprating of benefits restarted in April 2020 with benefits and tax credits linked to inflation rising by $1.7 \%$. In response to the COVID-19 pandemic, UC standard allowances and the Working Tax Credit basic element have also been increased by $£ 20$ a week until September 2021. Even with such temporary increases to benefits during the pandemic, out-of-work households are in receipt of less support in 2020 than in $2011-10 \%$ lower on average and $12 \%$ lower in workless households with children than it would have been in 2011 without any policy changes in the interim ${ }^{26}$. It remains to be seen whether such additional support is sufficient to protect low-income households, already feeling the impact of 4 years of reduced real value of benefits, from the economic impacts of COVID-19 and risk of food insecurity.

\section{Benefit sanctions and conditionality}

During the recent period of austerity and welfare reform it is not only the net amount of state support households receive that has been the focus of much debate in relation to food insecurity, restrictions in eligibility, increased conditionality and changes to the way benefits are administered have also come to the fore ${ }^{19}$. In 2018, the Trussell Trust reported that benefits were the most common form of income in $86 \%$ of referrals, and two-thirds of households referred to food bank provision had experienced problems with the benefit system in the last year ${ }^{19}$. Prime amongst the reported difficulties were delays during the switch from legacy benefits and employment to UC payments (the "five week wait"), the use of benefit sanctions stopping 


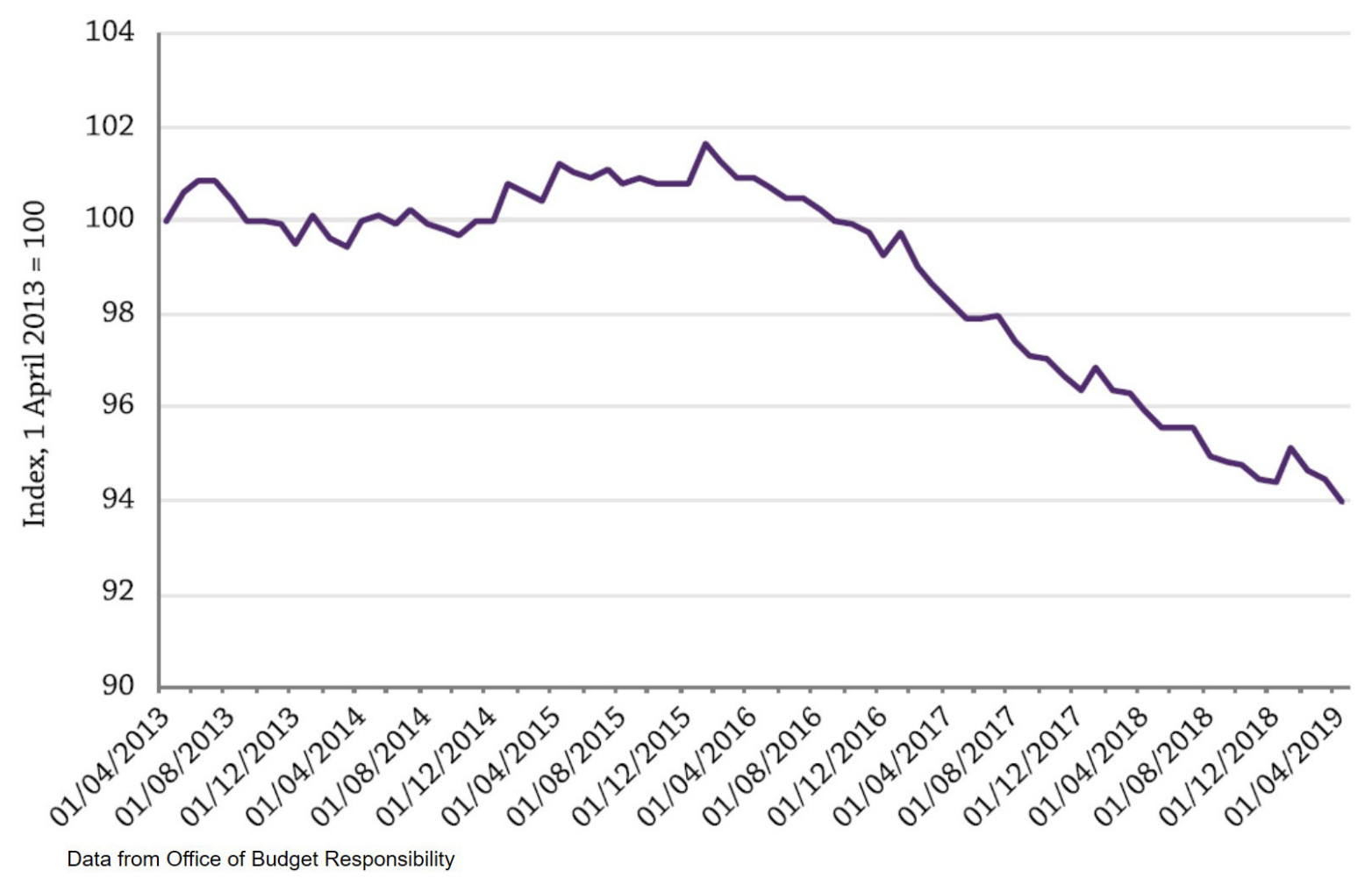

Figure 9. The real value of benefits since and compared a base index value in 2013. Reproduced with permission from Joseph Rowntree Foundation (2020). UK Poverty 2019/20. The leading independent report: https://www.jrf.org.uk/report/uk-poverty-2020-21.

benefit payments for up to 182 days, failed Personal Independent Payment (PIP) assessments', and introduction of the 'bedroom tax' ${ }^{4}$. Statistical modelling of Trussell Trust food bank usage over the years 2011/12 to 2018/19, controlling for the number of operating foodbanks, demonstrated these benefit related factors to be significant predictors of food bank parcel demand ${ }^{19}$. This shows UK welfare reforms and austerity measures introduced from the early 2010's have significantly contributed to a rising risk of food insecurity - as indicated by food bank use - even when controlling for the growth in the number and availability of food banks as a potential driver. These findings relate to the operation of the UK largest food bank provider but still likely substantially underrepresents the true scale of food insecurity since not all of those experiencing food insecurity will: (i) access a Trussell Trust food bank, and (ii) seek food bank support ${ }^{6}$.

${ }^{3}$ DWP assessment of eligibility for disability related support (introduced in April 2013) replacing the Disability Living Allowance for adults assessment

${ }^{4}$ The bedroom tax policy reduces housing benefit entitlement for those living in council or social housing with unoccupied bedrooms. Housing benefit is reduced $14 \%$ for 1 , and $25 \%$ for 2 or more, spare bedrooms
The use of sanctions is further reason to suspect that welfare reform since 2010 has constricted household budgets and potentially reduced the capacity of households to afford adequate food. The Welfare Reform Act 2012 laid the foundations of benefit sanctioning and conditionality that characterise the present social security system. Whilst policies such as benefit sanctioning were part of the benefit administration procedure prior to 2012, the severity and impact of sanctions increased from 2012. Figure 11 shows the total number of monthly JSA sanctions as a percentage of total number of claimants between 2000 and 2016. Whilst there were signs of increased sanction rates from 2007, the real rise in sanctioning followed election of the Coalition government in 2010. Sanction levels continued to increase after the introduction of the Welfare Reform Act 2012. This Act also amplified the impact of sanctions imposed from 2012 onwards by increasing the length and severity of the sanctions and the numbers of claimants subject to conditionality - and subsequent sanction - to higher levels than ever before ${ }^{40}$. At the peak of sanction referrals in 2013, the Oakley Review of JSA sanction policies was undertaken. The subsequent report broadly recommended better communication of conditionality requirements and processes for claimants $^{41}$. JSA sanction rates fell fairly consistently from 2013 up to 2016. There is some debate regarding what caused the fall 


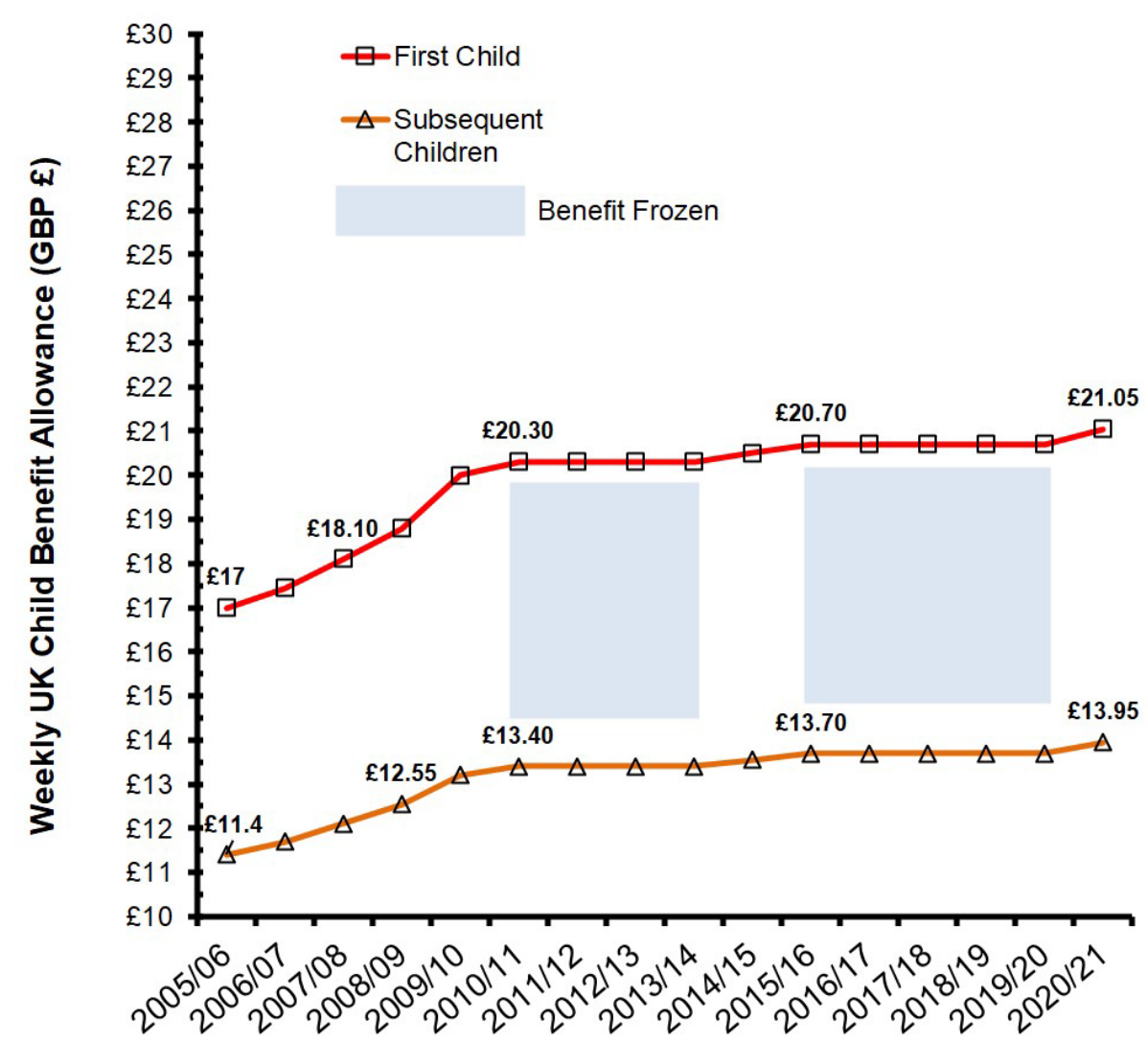

Figure 10. UK child benefit entitlement by child 2005/06 - 2020/21. Data from HM Revenue \& Customs: https://assets.publishing. service.gov.uk/government/uploads/system/uploads/attachment_data/file/691948/Child_Benefit_Commentary_August_2017.pdf; https:// www.gov.uk/government/publications/rates-and-allowances-tax-credits-child-benefit-and-guardians-allowance/tax-credits-child-benefitand-guardians-allowance\#child-benefit-rates.

in JSA sanctions. The transfer of claimants to UC during the initial roll-out from 2013 onwards certainly accounts for much of the fall but there is also evidence of a reduction in the previously applied pressure on DWP staff to make sanction referrals from 2013 onwards $^{42}$ (see cpag.org.uk/david-webster for a comprehensive overview and regular updates of sanction data).

Figure 12 shows the sanction rate and sanction length for both UC Live and Full service as reported between August 2015 February 2020. Overall, the UC monthly sanction rate was reported to be falling from a peak of approximately $9 \%$ in 2017 to just over $2 \%$ at the beginning of 2020 . Over the period of rolling out UC the level of claimants subject to conditionality therefore subject to facing sanction - has fallen from $81 \%$ in August 2015 to $60 \%$ in $2020^{43}$. In total, $84 \%$ of UC sanctions lasted 13 weeks or less since August 2015 with a median length of 29 days $^{43}$. However, reporting of sanction data has been beset with methodological issues and corrections. Indeed, the DWP withdrew all data on the duration of UC sanctions in November 2020 whilst the methodology is investigated ${ }^{44}$. This data has yet to be reinstated at the time of writing so the presented data on sanction length has to be treated as unconfirmed. The use of sanctions has continued in broadly the same manner for UC as for JSA. However, a number of key features of UC sanctions have increased the severity and impact of the penalty. Firstly, UC sanctions are longer since they can be issued to run consecutively rather than concurrently. Hardship funds available to support claimants during sanction periods have also become automatically repayable from future UC payments, effectively placing claimants in debt to the DWP. Hardship repayments taken from future UC benefits are set at the same rate at which the hardship repayment is lower than the benefit received $(40 \%)$. This effectively results in the claimant being under sanction for 2.5 times longer than length of the original sanction whilst they repay the hardship debt ${ }^{45}$. There have also been changes to sanction procedures that specifically impacts demographic groups most at risk of food insecurity. For example, lone parents with children would have previously lost $20 \%$ of benefit entitlements under sanction. Under the UC regime lone parents with a child between 2 and 5 years lose $100 \%$, and those with a child aged 1 year lose $40 \%$ of their standard allowance ${ }^{46}$. Individuals with a disability are also known to be more vulnerable to poverty and food insecurity ${ }^{19,47}$. Benefit 


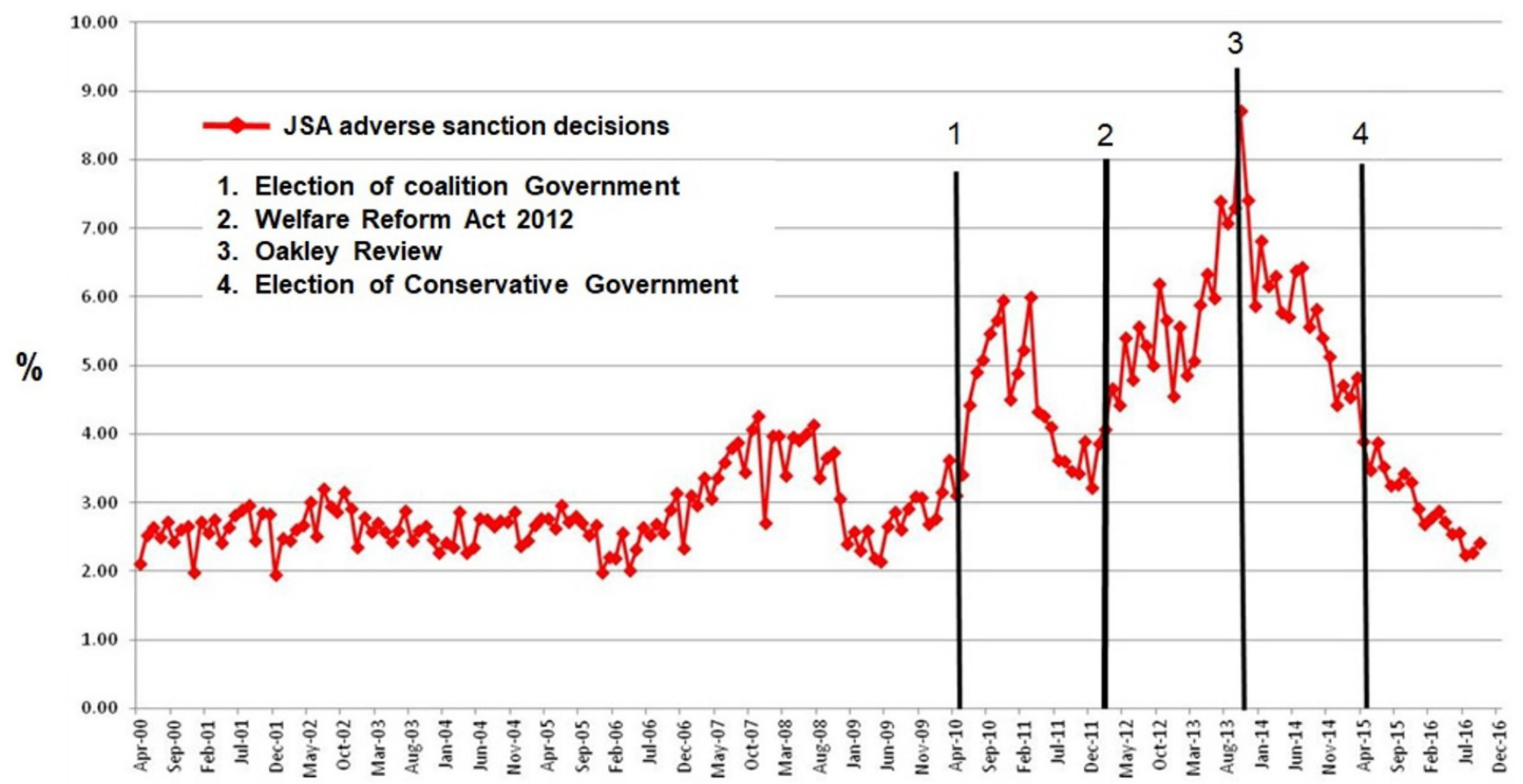

Data taken from DWP Stat-Xplore and NOMIS

Figure 11. Adverse JSA benefit sanction decisions per month as a \% of claimants, April 2001 - September 2016 (represents all sanctions imposed prior to subsequent appeals or reversals). Adapted and reproduced with permission from Webster, D. (2017). BRIEFING: Benefit Sanctions Statistics: JSA, ESA and Universal Credit. Feb. 2017: https://cpag.org.uk/david-webster.

A

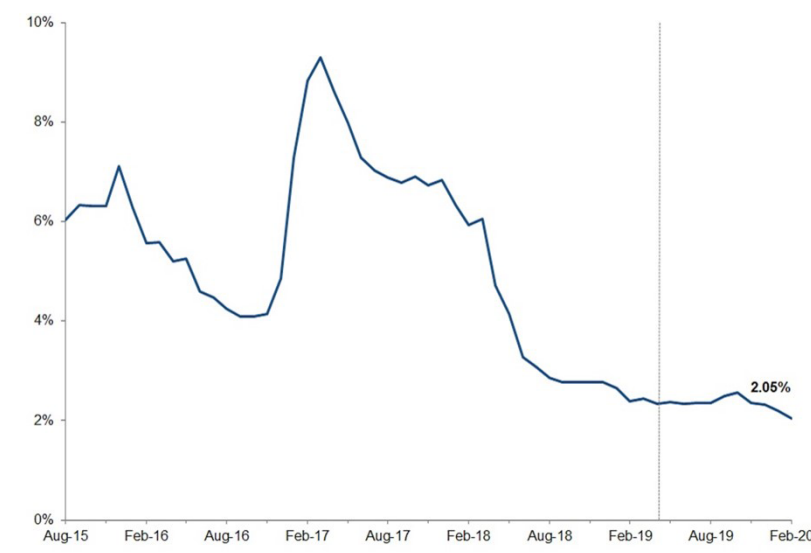

"The sanction rate is calculated as the proportion of people on each benefit on the same day that the claimant count is ecorded with a deduction from their benefit due to a sanction Comprises data from Live and Full Universal Credi
B

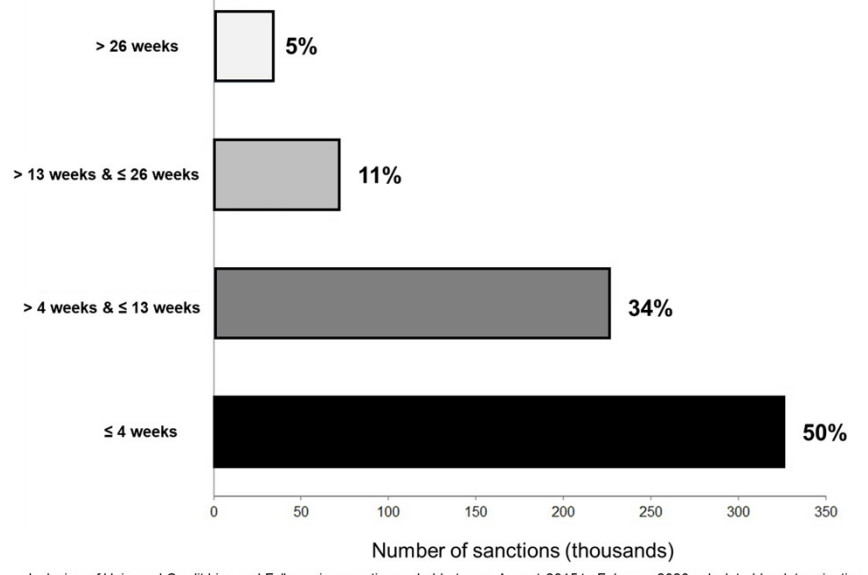
Inclusive of Universal Credit Live and Full service sanction ended between August 2015 to February 2020 calculated by
number of weeks a claimant shows a drop in benefit. Multiple, consecutive sanctions are counted as one sanction

Figure 12. A). Total UC claimants (Live and Full service) with a sanction deduction, as a proportion of UC claimants, August 2015 - February 2020; B). UC (Live and Full service) sanctions completed by length of sanction (thousands), August 2015 - February 2020. Both data sets have been suspended subject to review. Data from Department of Work \& Pensions (experimental statistics): https://www.gov.uk/government/ statistics/benefit-sanctions-statistics-to-january-2020-experimental/benefit-sanctions-statistics-to-january-2020. 
claimants with a disability have previously been shown to be more likely to be subject to sanction under legacy benefits ${ }^{48,49}$. However, it is not yet possible to ascertain the impact of UC sanctions on claimants with disabilities as the DWP does not publish sufficient data to permit this analysis.

In a parliamentary committee meeting on the effectiveness of sanction use in 2018, the Joseph Rowntree Foundation acknowledged that "sanctions by nature have to threaten some level of hardship. But this should not result in destitution" ${ }^{50}$. The imposition of sanctions must be considered a direct and immediate pathway to poverty, destitution and, by extension, food insecurity. The falling rates of sanctioning mask the increased severity of sanctions imposed and the longer-term effects on those that have faced them. The amount of all debt repayment deductions reclaimed from UC entitlements increased from 7\% ( $£ 9$ million from $£ 140$ paid) in April 2017 to $10 \%$ (£39 million out of $£ 410$ million paid) in October $2018^{51}$. In 2020, the Trussell Trust reported that their food bank users were more frequently in debt to the government than friends and payday loan companies; $47 \%$ reported debt arrears to the DWP as a result of loans and benefit overpayments ${ }^{52}$. The legacy of the significant rise in sanctions enacted during 2010-2013 may also still be impacting households that were pushed into a cycle of debt. There is no doubt sanctioning has pushed the income of households already facing poverty below the official benefit scale, i.e. households routinely receiving less income than that presumably considered to be the minimum required to pay for the costs of living. The withdrawal of all state benefits for weeks will inevitably push households into debt and reduce spending on essentials such as food.

Restrictions to movement and social contact during the COVID-19 pandemic resulted in the suspension of new sanctions from March 2020. Many lengthy existing sanctions were carried over the suspension with 12,643 claimants initially being reported as still under sanction by July $2020^{53}$. The DWP has since significantly revised this Figure to 6,949 claimants in August $2020^{54}$. There is still no evidence to demonstrate the use of sanctioning is efficacious in its aim of increasing the number of claimants seeking and finding employment or increased hours of employment. The DWP review of the effectiveness of sanctions is two years overdue and statistics related to sanctions are lacking crucial detail and are routinely withdrawn and revised.

\section{Housing costs}

Housing costs may provide a good indication of the money available to households to spend on other essential living costs since they account for a significant proportion of a household's expenditure. Poverty indicators are also higher when calculated AHC deductions reflecting that households at the lower end of the income distribution tend to spend a greater proportion of their income on housing. This means low-income household budgets are more sensitive to the effects of fluctuations in housing costs. A number of significant changes in UK housing over the last 20 years have had implications for low-income households. Firstly, the nature of UK housing tenure has drastically transformed with a significant shift to privately rented housing, particularly amongst young adults. This reflects shifts across the income distribution with significant drops in availability of social housing affecting households at the bottom, and falls in owner-occupation at the top, of the income distribution ${ }^{55}$. The UK social housing sector has been shrinking since the Right to Buy scheme was introduced in the 1980s with little attempt to replace lost social housing. Council-owned social housing stock declined from 30\% in 1981 to less than $8 \%$ by $2017^{33}$. In $2018 / 19$, it is estimated only $7 \%$ of social housing needed to meet the yearly demand of social rentals was completed ${ }^{56}$. These tenure shifts have resulted in a significant increase in households living in less secure and often more costly housing in the private sector. Indeed, the proportion of households living in private rented accommodation has risen from $11 \%$ in $2005 / 6$ to $19 \%$ in $2018 / 19$ (see Figure 13 for UK tenure trends 2005/6 - 2018/19). Private renting is the only tenure type to have shown consistent growth since 2005.

There is evidence to suggest this shift in UK housing tenure may disproportionately affect low-income households. Bailey ${ }^{57}$ cross tabulated data from the FRS with relative poverty data to identify the tenure status of households living $60 \%$ below the contemporary equivalised median income (AHC). This analysis highlighted a significant shift to private renting in young adults under 40 living in relative poverty. Figure 14 shows the share of adults under 40 in relative poverty living in owner occupied, social rented, privately rented housing and those living care of/rent free - defined as adults within the household who are neither the householder nor the partner of the householder; typically adult offspring of the householder. Since 2005 the proportion of young adults in relative poverty living in private rented housing has increased from $27 \%$ to $42 \%$ resulting in more impoverished young adults living in privately rented housing than owner occupied and socially rented accommodation combined ${ }^{57}$. Bailey's analysis also highlighted that $36 \%$ of children living in poverty live in privately rented accommodation.

The Joseph Rowntree UK poverty report 2020/21 highlights a combination of high housing costs in the private rented sector combined with falling levels of Housing Benefit provision have increased the vulnerability of low-income households to poverty ${ }^{38}$. This increased pressure on low-income households is not limited to private rentals. Figure 15 shows households spending more than one-third of their income (including Housing Benefit) on housing costs as a function of tenure. Renting privately is indeed associated with a higher likelihood of spending over a third of income on housing. However, social housing has not been immune to rising housing costs with a growing proportion of households since 2011 spending over a third of their income on housing in this sector. There is evidence to suggest those most vulnerable to poverty, and subsequent food insecurity, are most vulnerable to the effects of high housing costs. Figure 16 shows the proportion of the UK working age adults that spend more than one-third of their income on housing costs (net of Housing Benefit) between 2004/5 and 2016/17 separated into five income quintiles. 


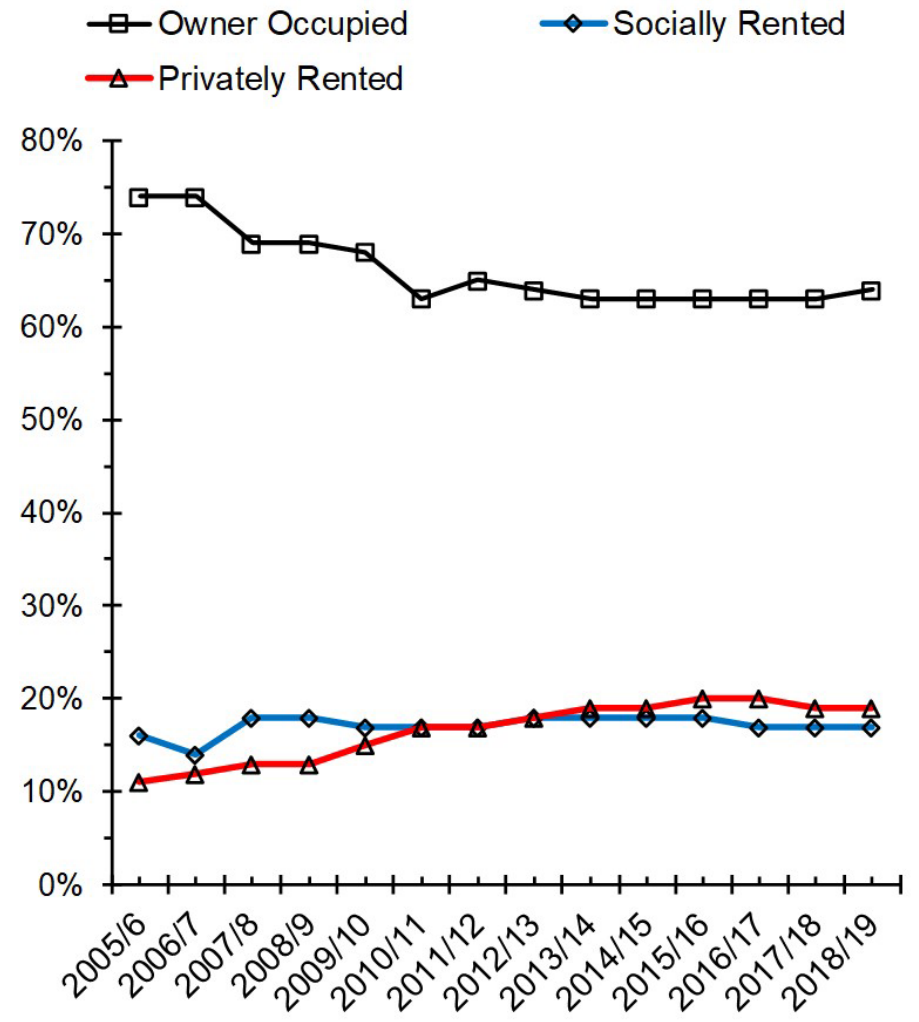

Owner occupied = owned outright and with mortgage

Figure 13. UK housing tenure trends between 2005/6 - 2018/19. Data from Family Resources Survey: https://www.gov.uk/government/ collections/family-resources-survey--2.

The Figure clearly shows the difference in proportion of income spent on housing costs across the income distribution. Housing costs have accounted for over one-third of income in nearly $40-50 \%$ of the poorest households over the last 15 years. Households spending more than one-third of their income on housing costs has risen from $39 \%$ in $2004 / 5$ to $47 \%$ in $2017 / 18$ in the poorest quintile whilst higher-income households have seen relatively no change during this period.

As the cost of housing accounts for a growing proportion of a household's income it is inevitable cutbacks on other essentials - such as food quantity and quality - will be forced upon some of the worse affected households. This is likely to have intensified during the COVID-19 pandemic as many households faced a further $20 \%$ drop in income under the furlough scheme and as a result of underemployment. Private renters in low-income households are likely to have faced significant economic impact since these households are overrepresented in the economic sectors hardest hit (e.g. retail, entertainment, service industries) ${ }^{38}$. Whilst support and protections for private renters were introduced during the pandemic, many will have faced significant hardship and insecure housing. In the social housing sector, the pandemic increased the prevalence of rent arrears and reduced income for poorer households. A poll by the Joseph Rowntree Foundation in October 2020 found $37 \%$ of social renters reported having to cut down on food spending since the start of the pandemic; $8 \%$ having to specifically reduce food spending for children ${ }^{33}$.

\section{The cost of food}

Income available to a household to spend on essential items such as food is not the only indicator that needs to be considered when examining the potential conditions that may increase vulnerability to food insecurity. The price and affordability of food are also primary determinants of a household's capacity to access the food needed to maintain an adequate diet as well as influencing food choices ${ }^{58}$. Figure 17 shows the price of food and non-alcoholic beverage in real terms in the 


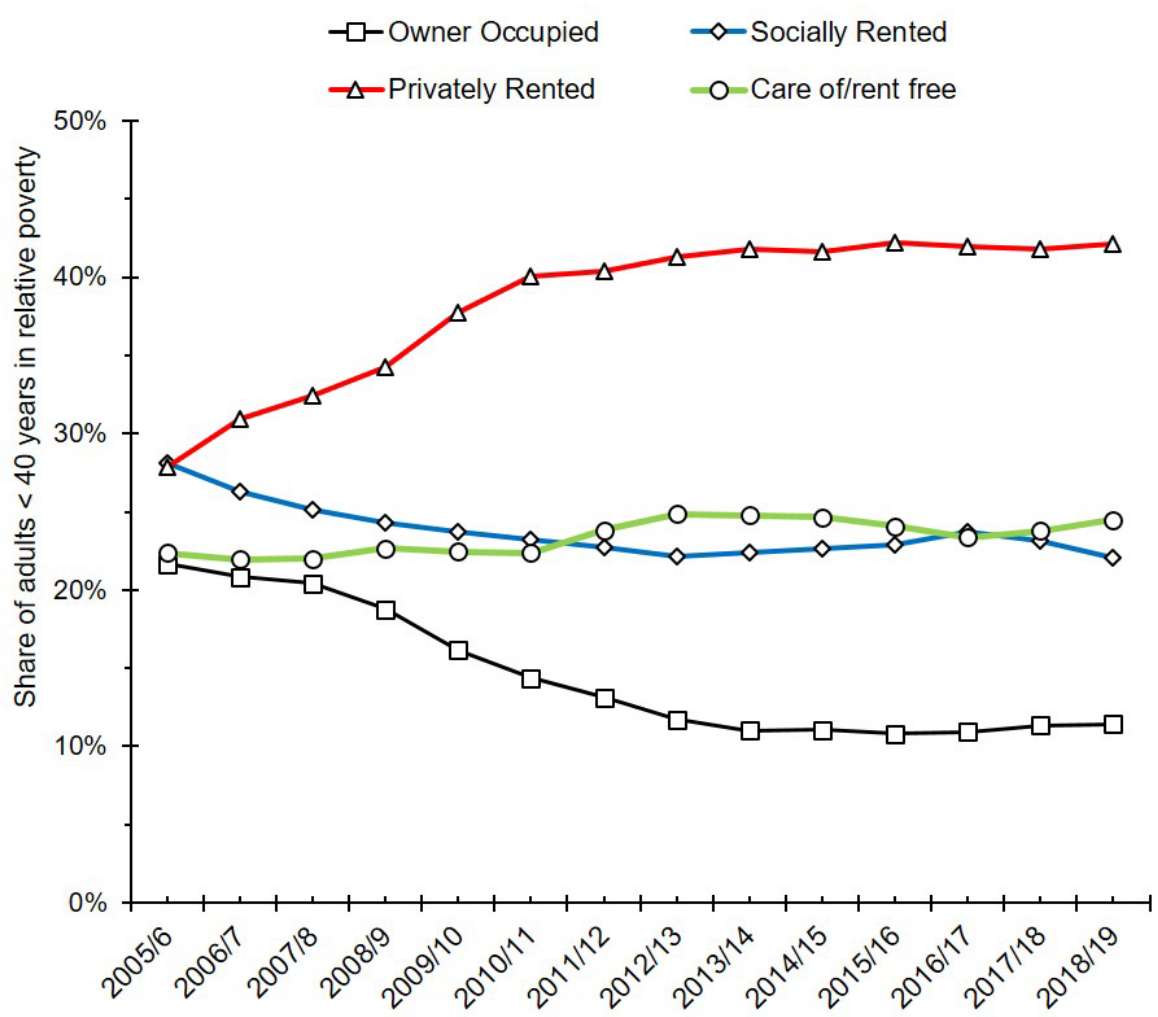

Original analyses combined data from Family Resources Survey and Households Below Average Income statistics. Poverty defined as households below $60 \%$ of contemporary income. Owner occupied $=$ owned outright and with mortgage

Figure 14. Housing tenure status of adults < 40 living in relative poverty (AHC) 2005/6 - 2018/19. Adapted with permission from analyses by Bailey, N. (2020) https://doi.org/10.1371/journal.pone.0228273.

UK since 2005. Spikes in the price of agricultural commodities and oil since 2007 combined with high inflation contributed to a trend in rising food prices from 2009 , reaching a peak in $2014^{59}$. These rising prices coincide with the period the UK faced the fallout of recession when household budgets in low-income households would have been reduced. Whilst food prices started to fall after 2014, they remain higher than those pre-2008.

To assess the impact of food prices on low-income households it is not sufficient to examine the price of food in isolation since it does not account for fluctuations in household budgets. The share of household budget that is spent on food gives a clearer indication of the relative affordability of food. This is of particular importance to low-income households as they typically spend less per person but a greater proportion of their total income on food $^{60}$. As a consequence, poorer households face a disproportionately greater impact of rising food costs.
Figure 18 shows the proportion of household income spent on food and non-alcoholic drinks from 2003 to 2018 in all UK households and lowest $20 \%$ of households by equivalised income. The disparity in the amount of household budget expended on food is clear. As expected, an increased proportion of household income spent on food coinciding with food price increases between 2008-2014 is shown. However, the proportion spent on food in the poorest $20 \%$ of households has since fallen below pre-2007 levels. In 2018/19 this still accounted for $14.7 \%$ of income in the poorest households compared to $10.5 \%$ in the UK as a whole.

Figure 19 illustrates the pressures on income as a result of the unaffordability of food in the poorest households by plotting $\mathrm{AHC}$ income in the lowest $5^{\text {th }}$ percentile against real term food prices between 2002 and 2018. An overall food price increase of $3.5 \%$ between 2002-2018 coincided with a reduction in AHC income in the lowest income households of $12 \%$ 


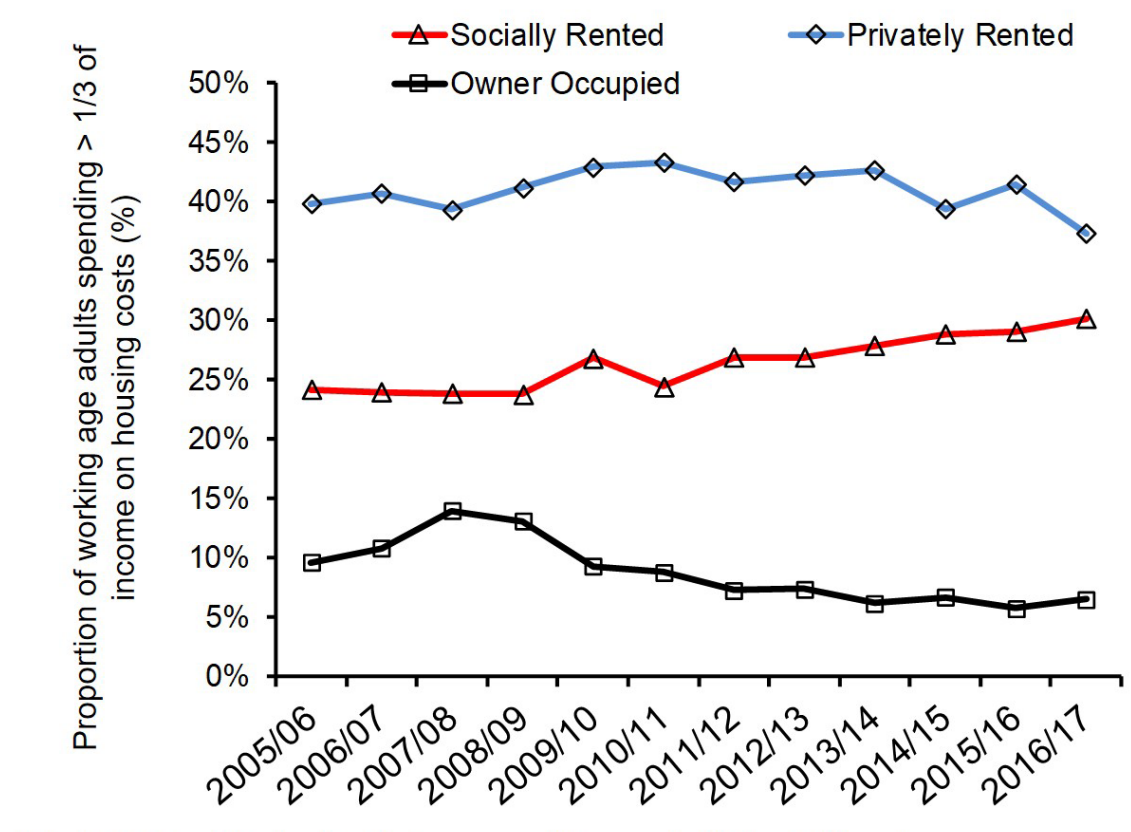

*Data is inclusive of Housing Benefit. Owner occupied = owned outright and with mortgage

Figure 15. Proportion of UK working age adults paying more than $1 / 3$ of income on housing costs by housing tenure type 2005/6 - 2016/17. Data from DWP HBAI statistics: https://www.gov.uk/government/collections/households-below-average-income-hbai--2.

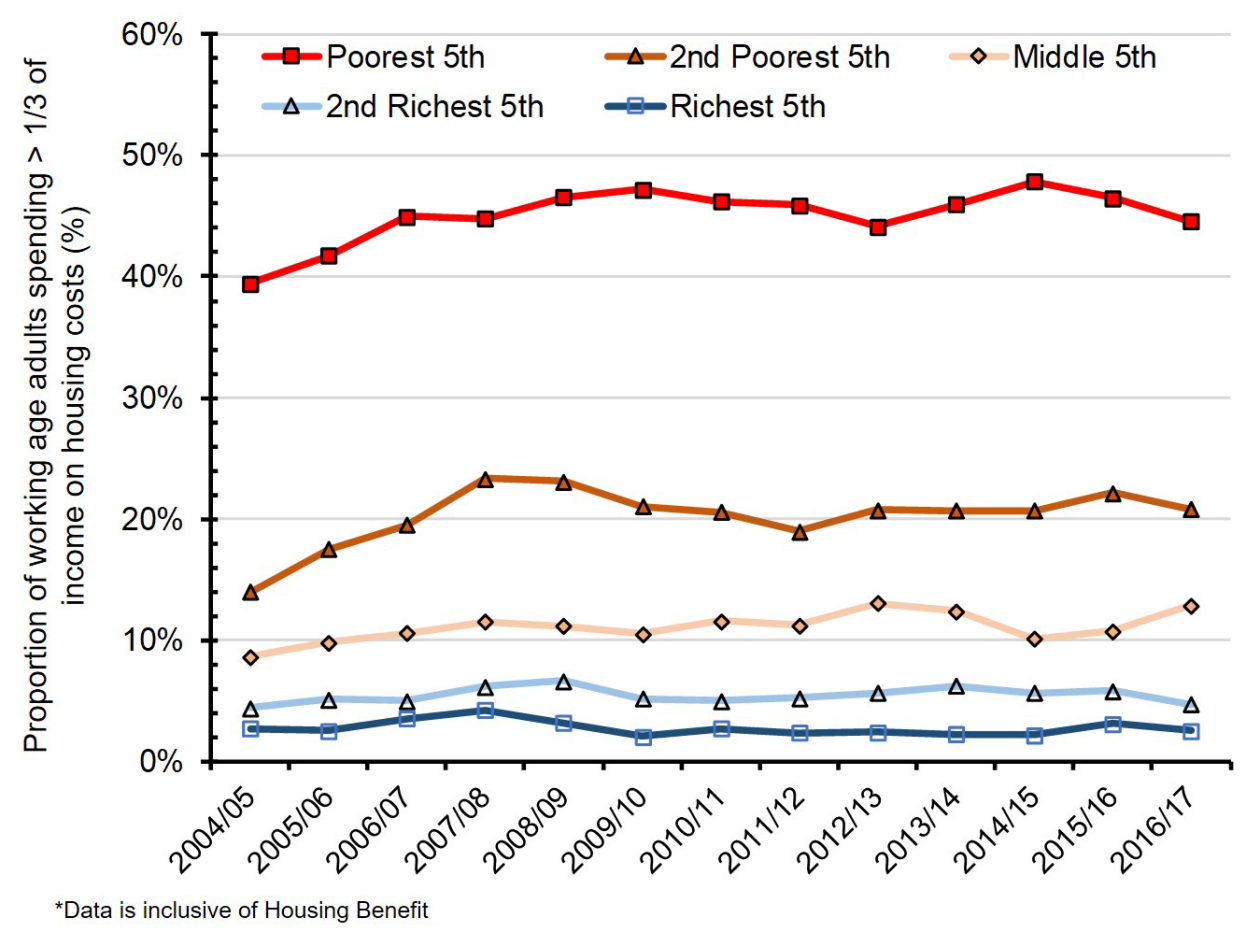

Figure 16. Proportion of UK working age adults paying more than $1 / 3$ of income on housing costs by income quintile 2004/5 - 2016/17. Adapted with permission from Joseph Rowntree Foundation: https://www.jrf.org.uk/data/working-age-adults-spending-morethird-income-housing-costs. Data from DWP HBAI statistics: https://beta.ukdataservice.ac.uk/datacatalogue/studies/study?id=5828\&type $=$ Data\%20catalogue. 


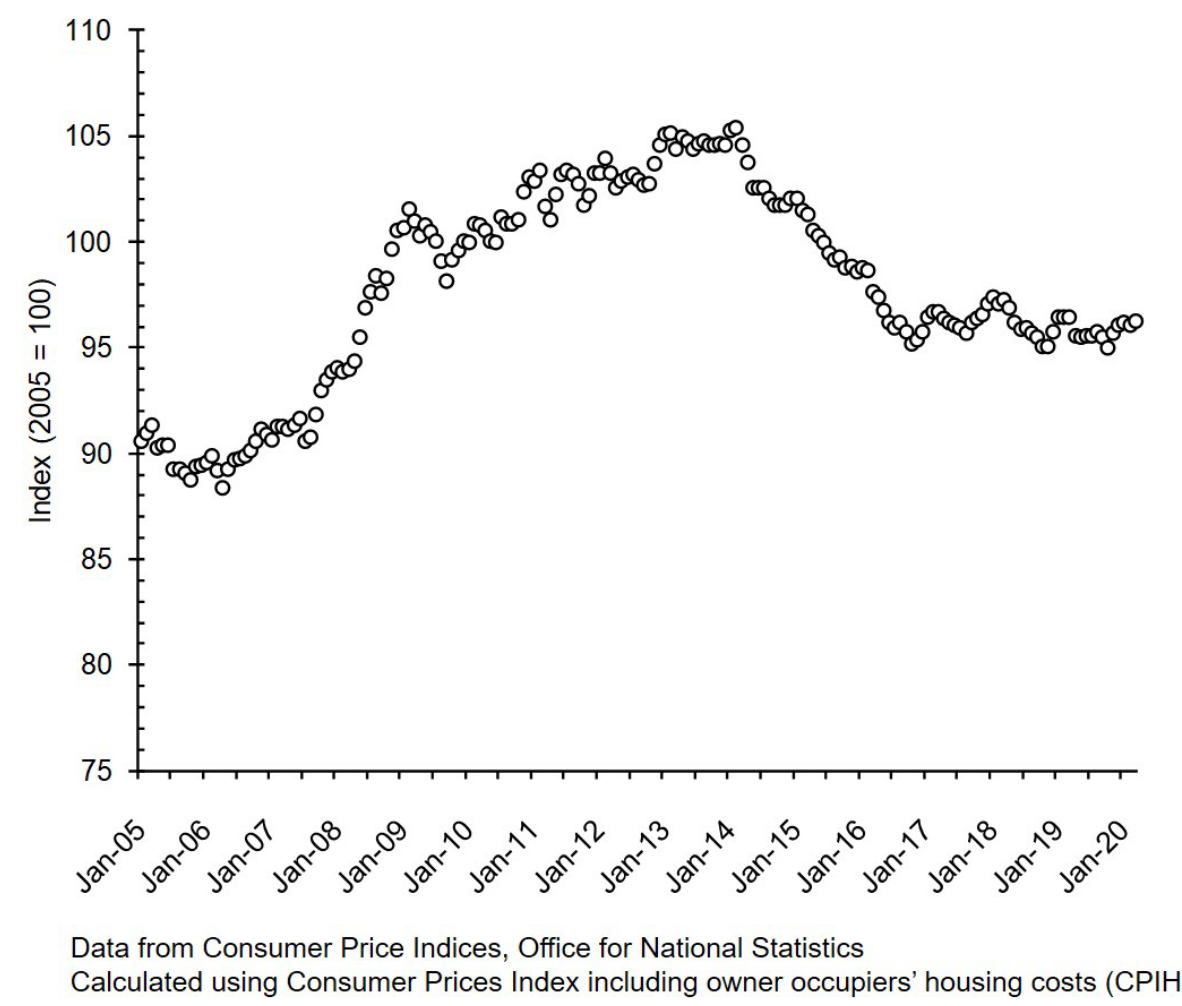

Figure 17. Monthly UK food and non-alcoholic beverage prices in real terms (adjusted for inflation in line with the Consumer Prices Index including owner occupiers' housing costs (CPIH), January 2005 to March 2020. Adapted from DEFRA: https://wwW.gov. uk/government/statistics/food-statistics-pocketbook/food-statistics-in-your-pocket-prices-and-expenditure.

during the same period ${ }^{59}$. Reduced affordability of food may increase the risk of food insecurity in terms of capacity to buy enough food for some of the poorest households. It is this reduced capacity to access a sufficient quantity of food, and often associated recourse to food bank provision to fill this gap, that for many typifies the common perception of food insecurity. However, most definitions of food insecurity emphasise both quantity and quality of food. Reduced food affordability is closely linked with food choice and the quality of food purchased ${ }^{58,61}$. Food insecurity is closely associated with a lower quality of diet, particularly a reduced intake of fruit, vegetables and dairy ${ }^{62}$. Reduced affordability of food is proposed to shift food purchases in the poorest household towards cheaper more energy dense food choices ${ }^{63,64}$; that is, when household budgets are constrained by economic factors, poorer households may maximise energy value for money ${ }^{60}$. Closer analysis of rising UK food prices since 2002 has shown that cost rises have been greater for healthier vs. less healthy foods types (indexed by a UK Food Standards Agency nutrient profiling model $)^{65}$. Analysis by the Food Foundation further demonstrated social inequity in the affordability of a healthier diet by comparing the cost of purchasing a diet of sufficient quality to meet the UK Government's Eat Well Guide to household expenditure and disposable income data from the 2015/16 Living Cost and Food Survey and Family Resources Survey ${ }^{66}$. A total of $26 \%$ of UK households, over half of which contained at least one child, would be required to spend over a quarter of disposable income AHC to meet the Eat Well Guide costs. Households with children in the lowest two income deciles (annual earnings $<£ 15,860$ ) would need to spend $42 \%$ AHC disposable income to meet the recommended dietary quality requirements ${ }^{66}$.

Evidence of poor income growth in the poorest households since 2013, rising food costs, and the affordability of healthier diets are likely to contribute to social inequalities in health by affecting the secure access to quality diets in the poorest households. For example, a shift to cheaper, energy dense, often nutrient poor, food choices has been proposed to account to some degree for the increased levels of overweight and obesity observed in low socioeconomic status groups, particularly women $^{67-69}$. However, the association between food insecurity and obesity in the UK is yet to be clearly characterised ${ }^{70}$ and much of this data is representative of the US food insecure population. 


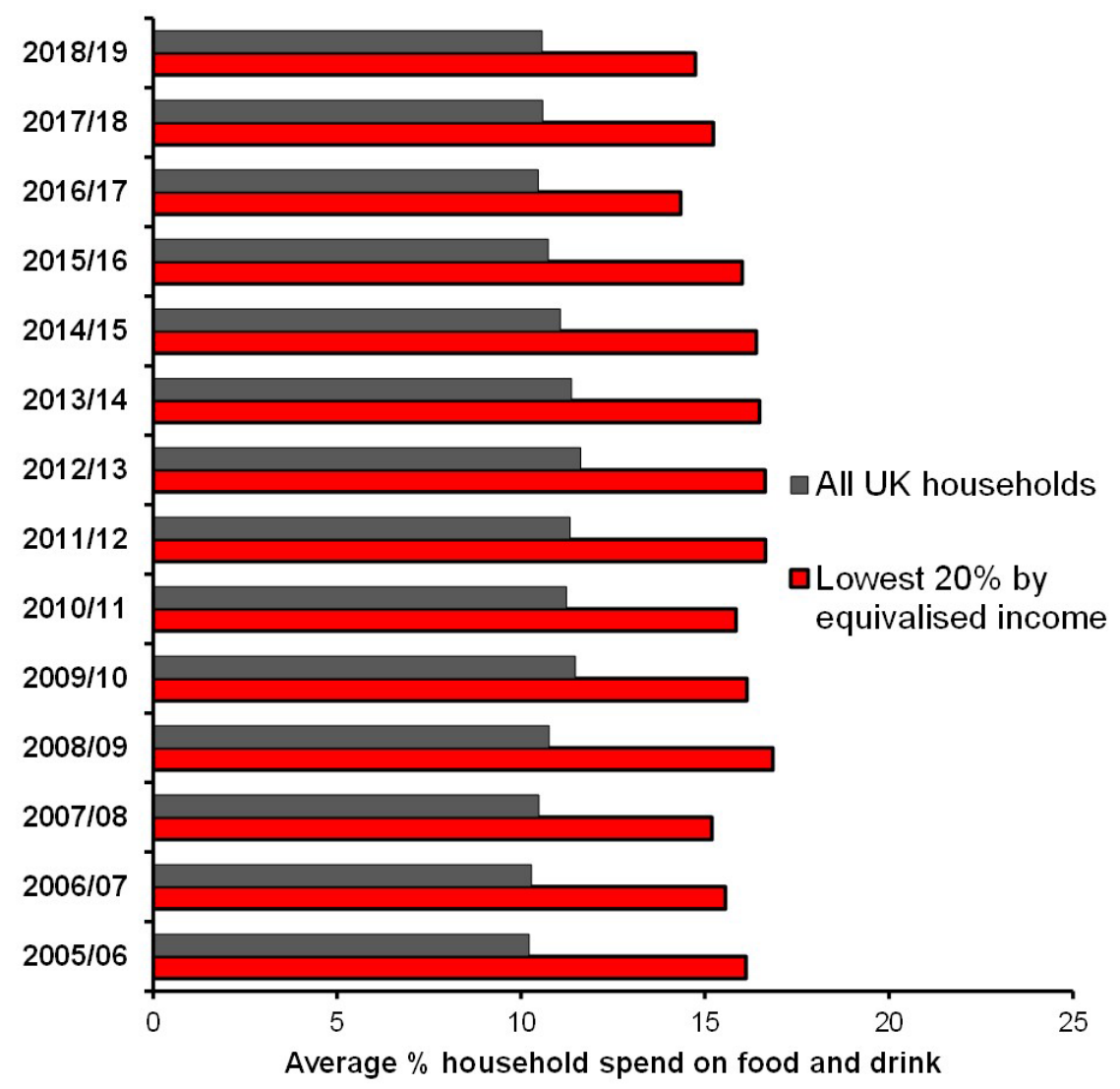

Figure 18. Proportion of household spend on food and non-alcoholic drink 2005/06 - 2018/19 in all UK households and lowest $\mathbf{2 0} \%$ of households by equivalised income. Data from Living Costs and Food Survey (Defra/ONS), Family Spending table 3.1e (ONS) https://www.gov.uk/government/statistics/food-statistics-pocketbook/food-statistics-in-your-pocket-prices-and-expenditure.

\section{Health indicators associated with poor nutritional quality}

Having focussed upon data that give an indication of economic conditions that may have promoted food insecurity over time, we now turn to data related to the potential consequences of food insecurity one would expect to see if individuals were unable to secure adequate nutritional intake. This includes direct measures such as the prevalence of malnutrition in the population, and indirect indicators of poor nutritional intake such as nutrition-related disease. Clearly, such markers are influenced by a complex array of variables and will not provide any accurate indication of the prevalence of food insecurity as such, but any significant movements in such markers over time, especially if they coincide with previously outlined economic trends, may permit a degree of insight into the potential prevalence of food insecurity.

\section{Malnutrition}

Malnutrition refers to a state in which an imbalance of energy and nutrients results in measurable adverse effects on tissue, body shape, size and composition, and/or function. Malnutrition can be a result of undernutrition and overnutrition (obesity) - the double burden of malnutrition. An individual can be underweight or overweight and be malnourished if their diet lacks the nutrients required to maintain healthy function. In 2018, the UK Stakeholders for Sustainable Development (UKSSD), a cross-sector network campaigning for action to meet UN Sustainable Development Goals, reported that the UK was struggling to address malnutrition in all its forms. The report considered socioeconomic status a key driver in the failings to provide healthy, sustainable, diverse diets for the UK population ${ }^{71}$. This coincided with the NHS reporting a resurgence in so-called 'Victorian Diseases' which were prevalent during historical periods of severe poverty in the mid-to-late $19^{\text {th }}$ Century. This includes undernourishment, scurvy and rickets - diseases associated with an impoverished diet. Malnutrition is commonly used to refer only to undernutrition. In this section, malnutrition will be employed to denote undernutrition, and overweight and obesity to denote overnutrition. 


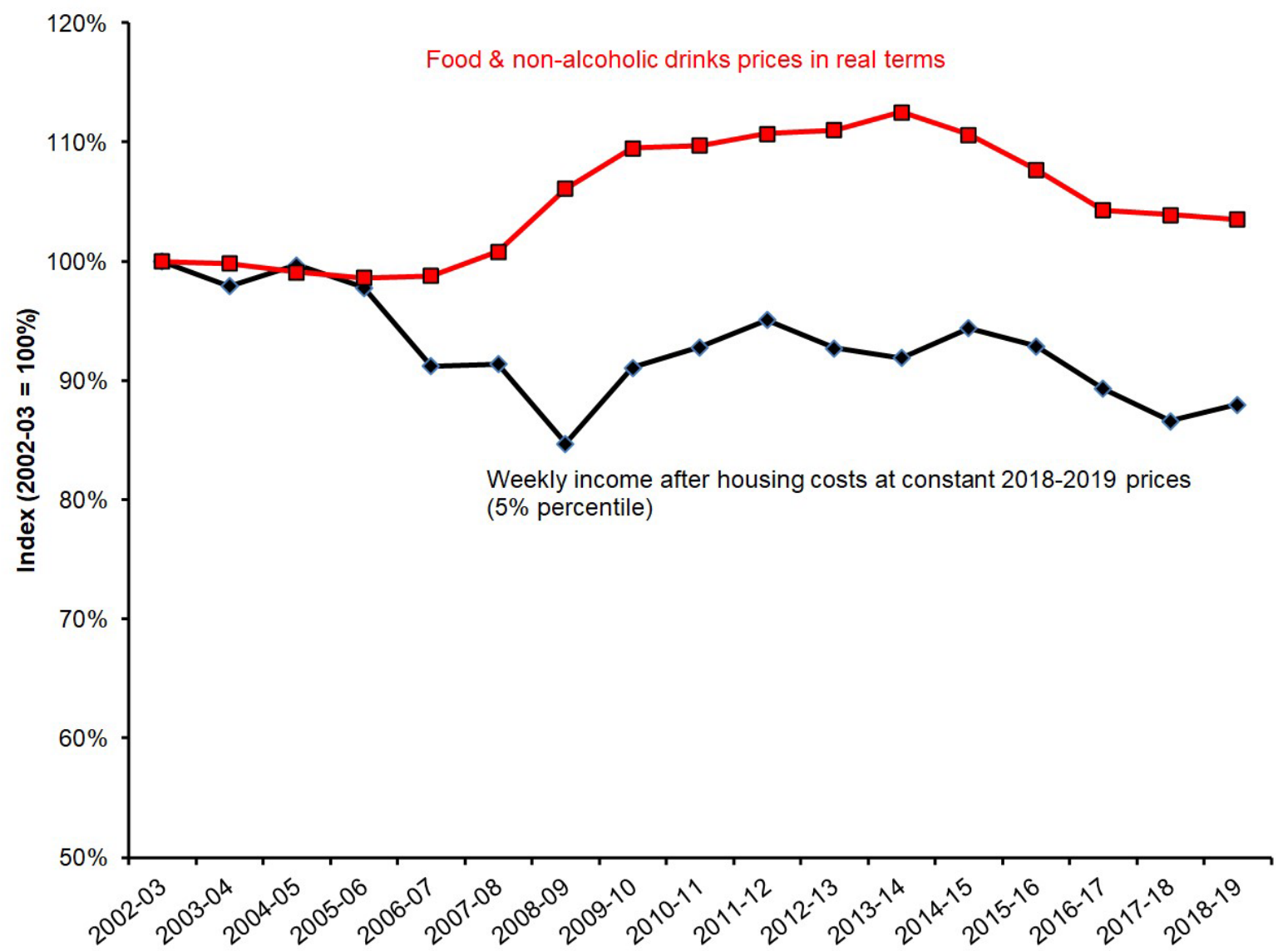

Data from Living Standards, Poverty and Inequality in the UK, 2019; Institute for Fiscal Studies

Figure 19. UK lowest $5^{\text {th }}$ percentile household income (after housing costs) and food prices in real terms 2002 - 2018. Adapted from DEFRA: Food Statistics in your pocket: Prices and expenditure: https://www.gov.uk/government/statistics/food-statistics-pocketbook/ food-statistics-in-your-pocket-prices-and-expenditure.

Malnutrition is commonly defined as a BMI $<18.5 \mathrm{~kg} / \mathrm{m}^{2}$, $>10 \%$ unintentional weight loss in the last 3-6 months, or a BMI $<20 \mathrm{~kg} / \mathrm{m}^{2}$ and $>5 \%$ unintentional weight loss within the last 3- 6 months $^{72}$. There is no single, robust measure of the prevalence of malnutrition in the UK population. An often cited estimate of malnutrition is taken from the British Association for Parenteral and Enteral Nutrition (BAPEN) who report 3 million people, 1.3 million of which are over 65 years, of the UK population are malnourished ${ }^{73}$. However, this estimate relates to data from 2005-2011 only and appears not to have been updated since. The only longitudinal data directly measuring malnutrition comes in the form of reported deaths and hospital admission data. Figure 20 shows the number of reported deaths in England as a result of malnutrition or for which malnutrition was mentioned in the death certificate since 2005. This data refers to undernutrition or starvation as defined by
WHO ICD-10 ${ }^{74}$. The number of deaths for which malnutrition was an underlying cause or mentioned as an underlying cause or contributory factor nearly doubled between 2005 and 2017. However, there are many reasons an individual may be undernourished, particularly as a direct result of ill health, so it is inappropriate to automatically assume undernourishment to be a consequence of deprivation.

Malnourished adults account for a significant proportion of hospital admissions, particularly from care homes ${ }^{75}$. Figure 21 shows the number of UK hospital finished admission episodes registered as having a primary or primary or secondary diagnosis of malnutrition between 2007 and 2018. Admissions with a primary diagnosis of malnutrition more than doubled during this period; admissions with a primary or secondary diagnosis almost quadrupled. A diagnosis of ICD-10 code of 


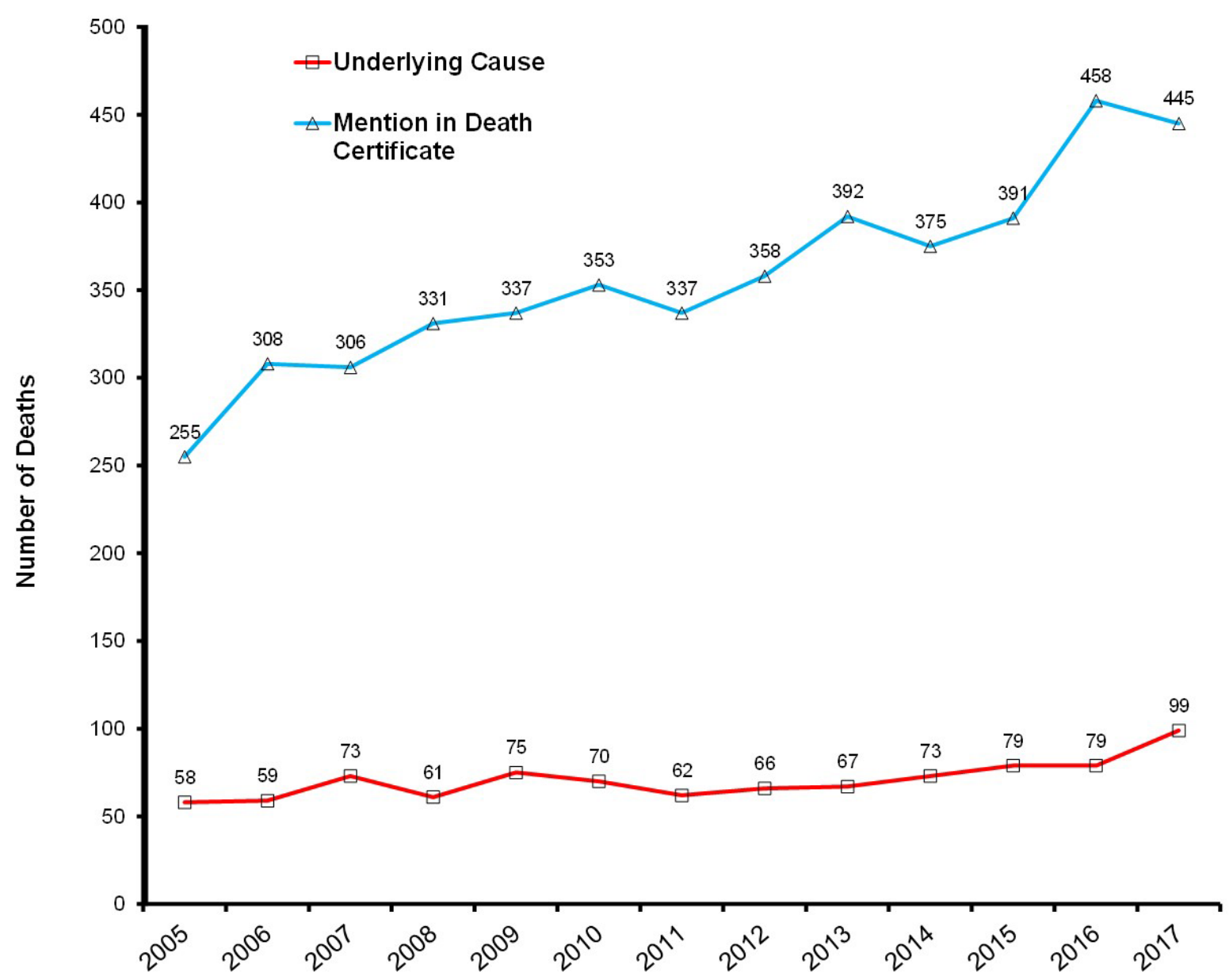

Cause of death defined as per the International Classification of Disease, 10th Revision (ICD-10) codes E40-46 'Malnutrition' or T73.0 'Effects of hunger'. Deaths reflect when registered rather than occuring in each calender year

Figure 20. Number of deaths for which malnutrition was (a) the underlying cause of death, or (b) mentioned anywhere on the death certificate as underlying cause or contributory factor, persons, England, deaths registered between 2005 - 2017. Data from: ONS 2018: https://www.ons.gov.uk/peoplepopulationandcommunity/birthsdeathsandmarriages/ deaths/adhocs/009065deathswheremalnutritionwastheunderlyingcauseofdeathorwasmentionedanywhereonthedeathcert ificatepersonsenglandandwales2001to2017.

malnutrition indicates the patient was diagnosed and received treatment for malnutrition during the hospital stay. The cause of malnutrition is not recorded. Therefore, it is not possible to disentangle those admitted to hospital with an underlying medical condition for which malnutrition is an associated comorbidity, from those experiencing undernutrition due to some other factor such as poverty or reduced social provision. However, an increase of this magnitude cannot be accounted for by malnutrition secondary to a medical condition alone; additional factors must account for a proportion of the increase in malnutrition cases.

Older adults are often most at risk from malnutrition, with evidence of inadequate dietary intake both in older adults living in the community and in social care ${ }^{73}$. Previously outlined data shows that older adults in the UK have experienced significant improvements in poverty levels and were largely protected from the recession in terms of income protection. This would suggest a level of protection from food insecurity. However, adults over 60 years have accounted for more than $50 \%$ of hospital admissions with a primary or secondary diagnosis of malnutrition between 2007 and 2017 (see Figure 22). A rise from $~ 50 \%$ of admissions in 2007 (for cases in which the age of patients was known) to $60 \%$ in 2017 has been recorded in those over 60 years. This Figure may also underestimate the extent of the problem since common admissions for falls or accidents in older adults may be as a direct consequence of the effects of malnutrition which may not be diagnosed or recorded. 


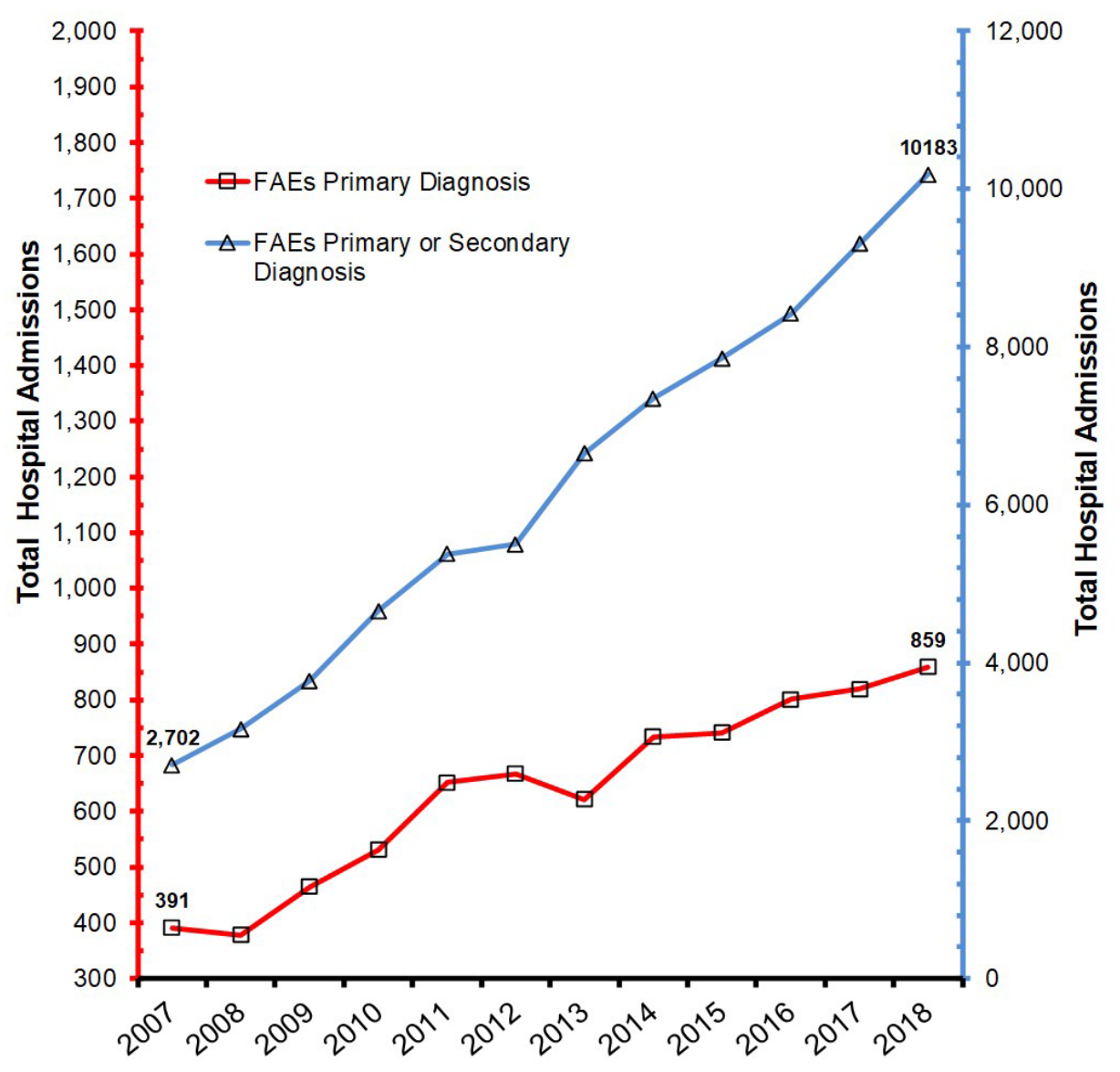

Figure 21. UK hospital Finished Admission Episodes (FAEs) with i) a primary diagnosis \& ii) a primary or secondary diagnosis of malnutrition, England, May 2007 - April 2008 to May 2018 - April 2019. Data from: NHS Digital: https://digital.nhs.uk/data-andinformation/find-data-and-publications/supplementary-information/2019-supplementary-information-files/victorian-diseases---hospitaladmissions.

This level of malnutrition in a section of the population is suggestive of an issue with access to food that has increased over time in spite of improvements to the economic status of older adults. Whilst the economic situation of the average pension age adult may have improved dramatically since the 1990 s, it has been fairly static since with approximately $15-20 \%$ of pension age adults having been in relative poverty since 2005 (see Figure 6). Welfare spending cuts during austerity are also likely to have impacted the level of social care service provision for older adults to help protect them from insecure access to food. This was highlighted by a review of 'meals on wheels' provision across the UK by Association for Public Service Excellence (APSE) in $2018^{76}$. Table 2 shows the proportion of UK Local Authorities offering meals on wheels service (directly or by external contract) in 2014, 2016 and 2018. Provision across the UK fell from 66\% in 2014 to $42 \%$ in 2018. Provision for older adults in the North East and North West, two regions most acutely affected by food insecurity, was only $17 \%$ and $13 \%$, respectively, in 2018. Such evidence of reduced care provision for older adults at home is particularly concerning since the vast majority of malnourished older adults live in the community ${ }^{73}$.

Potential causes of malnutrition in older adults are complex and should not be considered only as a potential direct result of reduced access to food due to individual economic circumstances. Indeed, as previously outlined, the first FRS food insecurity module for 2019/20 reported comparatively low food insecurity in older adult groups ${ }^{2}$. Social isolation, loneliness, bereavement, loss of appetite, impaired cognitive or physical capacity and mobility issues affecting access to shops have all been associated with reduced food intake in older adult populations $^{77,78}$. Whilst the recent FRS survey shows older adults are comparatively less likely to report being food insecure than younger cohorts, many are more likely to be vulnerable to reductions in levels of social care provision impacting their access to a sufficiently nutritious diet. Adult social care includes a broad range of non-medical services for individuals that need support with activities of daily living such as washing, feeding, housework or general mobility. This 


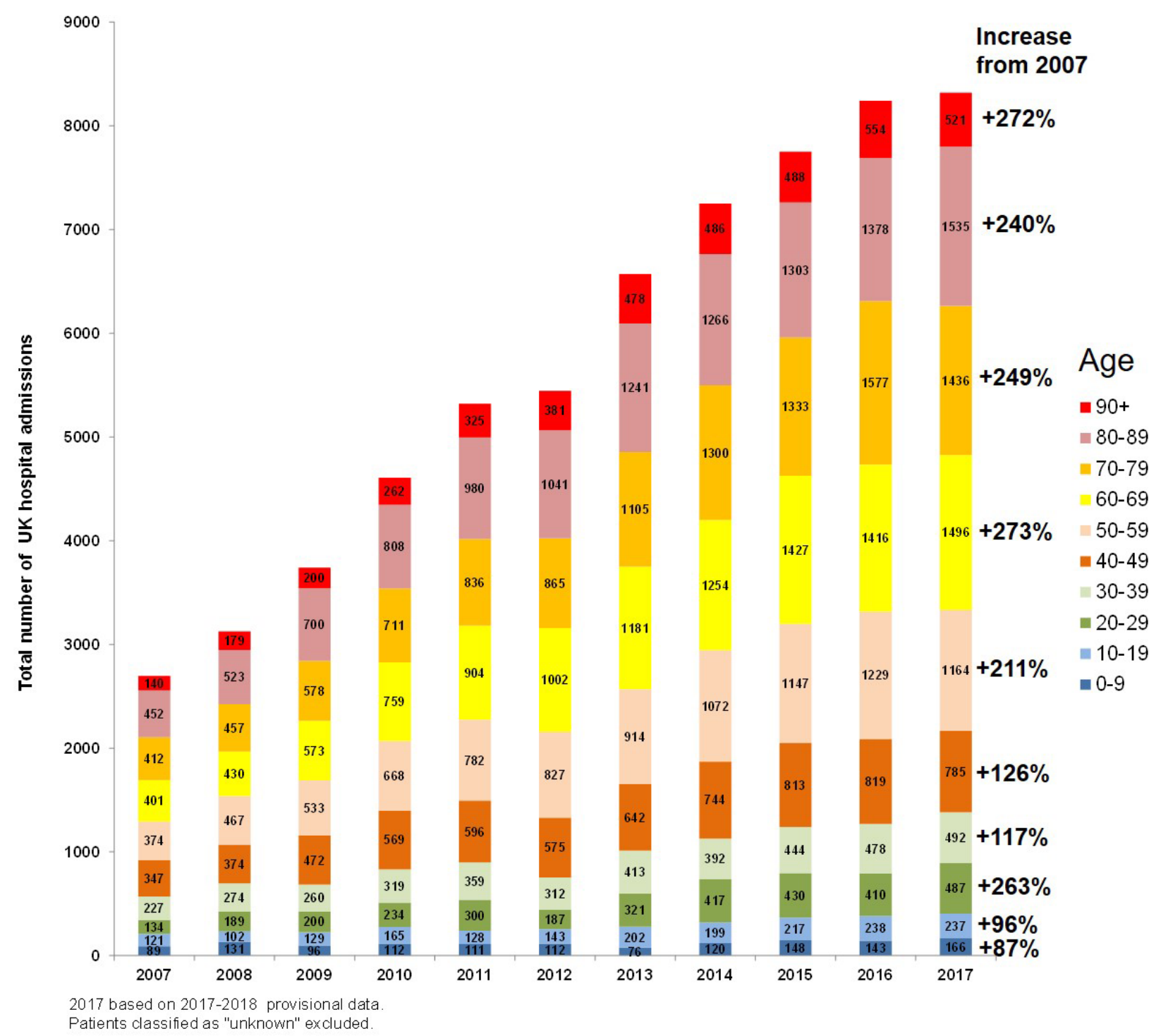

Figure 22. UK hospital Finished Admission Episodes (FAEs) with i) a primary diagnosis \& ii) a primary or secondary diagnosis of malnutrition, May 2007 - April 2008 to May 2017 - April 2018 by age group. Data from: NHS Digital: https://digital.nhs.uk/data-andinformation/find-data-and-publications/supplementary-information/2019-supplementary-information-files/victorian-diseases---hospitaladmissions.

includes the provision of, and/or support to, shop, cook and eat, nutritionally balanced meals. Social care funded in-home support or lunch clubs also provide a source of essential social contact which can mitigate the negative effects of loneliness and social isolation on appetite and dietary intake ${ }^{79}$. Austerity measures between 2010 and 2018 have resulted in an $18 \%$ reduction (in real terms) of total revenues available to local authorities that are responsible for the commissioning of social care provision ${ }^{80}$. An investigation by IFS reported that the austerity programme precipitated an $18.9 \%$ fall in social care spending on the over 65 s between $2009 / 10$ and $2017 / 18$. When accounting for a $19.3 \%$ population growth in adults over 65 years during this period, this translates to a $31.2 \%$ reduction in mean per-person social care spending in England for those over 65 years $^{81}$. These cuts to social care provision had direct effects on the health and well-being of older adults. Crawford et al.'s analyses estimates that between 2009/10 and 2017/18 social care cuts accounted for between a quarter and half of a 33\% increase in annual A\&E visits by older adults over 65 years $^{81}$. These negative effects were felt most by the oldest and those living in the most deprived neighbourhoods. There is little indication that circumstances will improve considering 
Table 2. Percentage of UK Local Authorities offering 'Meals on Wheels' Service (directly or by external contract).

\begin{tabular}{|c|c|c|c|c|}
\hline Country & Region & 2014 & 2016 & 2018 \\
\hline \multirow[t]{9}{*}{ England } & East of England & $64 \%$ & $64 \%$ & $45 \%$ \\
\hline & East Midlands & $88 \%$ & $50 \%$ & $50 \%$ \\
\hline & London & $69 \%$ & $59 \%$ & $41 \%$ \\
\hline & North East & $25 \%$ & $25 \%$ & $17 \%$ \\
\hline & North West & $48 \%$ & $17 \%$ & $13 \%$ \\
\hline & South East & $67 \%$ & $33 \%$ & $39 \%$ \\
\hline & South West & $71 \%$ & $53 \%$ & $41 \%$ \\
\hline & West Midlands & $60 \%$ & $53 \%$ & $47 \%$ \\
\hline & Yorkshire \& Humber & $50 \%$ & $44 \%$ & $20 \%$ \\
\hline Northern Ireland & & $100 \%$ & $100 \%$ & $80 \%$ \\
\hline Scotland & & $94 \%$ & $75 \%$ & $61 \%$ \\
\hline Wales & & $59 \%$ & $50 \%$ & $45 \%$ \\
\hline UK & & $66 \%$ & $48 \%$ & $42 \%$ \\
\hline
\end{tabular}

Taken from the Association for Public Service Excellence (APSE) report.

Available: https://www.publicsectorcatering.co.uk/sites/default/files/ attachment/nacc__meals_on_wheels_report_2018.pdf

a National Audit Office enquiry recently reported that $94 \%$ of councils in England with social care responsibilities expect to reduce social care budgets further in $2021 / 22^{82}$.

The full impact of COVID-19 and subsequent social restrictions and economic impacts on the levels of malnutrition in the UK is yet to be fully shown. However, it is clear older people face a significantly higher risk compared to the rest of the population both in terms of vulnerability to COVID-19 itself, and the effects of social distancing. Many older adults will have experienced significant social isolation during the pandemic. This increases the risk of insecure access to food and malnutrition as a consequence of increased difficulty accessing an adequate quantity and quality of food, and potential reduced appetite as a result of impoverished social contact ${ }^{83}$. Poor nutritional status is associated with reduced immune function and greater risk of communicable disease ${ }^{84}$ and may subsequently increase the susceptibility, and reduce the recovery potential, of older adults.

Figure 22 illustrates that the increase in UK hospital admission rates for which malnutrition was recorded as a primary or secondary diagnosis was not limited to older adults. Malnutrition diagnoses across all age groups has increased markedly since 2007. These increases have been more consistently pronounced in those over 60 years, however, malnutrition more than doubled in the 50-59 and 20-29 age ranges - $211 \%$ and $263 \%$, respectively. Increased awareness and improved screening of malnutrition in hospitals may account for some of the rise in reported admission cases. However, such a rise in reported malnutrition in younger age ranges is suggestive of a worrying trend. It is not possible to interpret the increased incidence of malnutrition in younger age groups as indicative of an increased prevalence of food insecurity, but it is suggestive of rising poor nutritional status in sectors of the population that are not typically malnourished in significant numbers. This is supported by evidence of a growing number of reported cases of 'legacy' diseases associated with poor nutrition. Figure 23 shows the number of hospital admission episodes with a primary and/or secondary diagnosis of scurvy or rickets between 2007 and 2018. Reported cases of scurvy have increased fairly steadily since 2008 with a marked spike in 2017; rickets cases spiked in 2011-12. Both scurvy and rickets have long been considered relics of the past in which impoverished sections of the population consumed inadequate diets. These spikes in reported cases, coinciding with the UK economic downturn, have been suggested to reflect a reduction in the quality of life of the poorest ${ }^{85}$, but it is not possible to establish the role, if any, food insecurity may have played in these disease trends. However, there is evidence to suggest poverty, which can be considered a close correlate of food insecurity, has played a key role in inequitable dietary related outcomes. For example, dental health can be considered a proxy indicator of diet quality. The dental health of children in the UK has shown steady improvement since 2007 (see Figure 24); however, dental decay prevalence is clearly related to economic position with worse dental health evident the lower children fall on the socioeconomic 

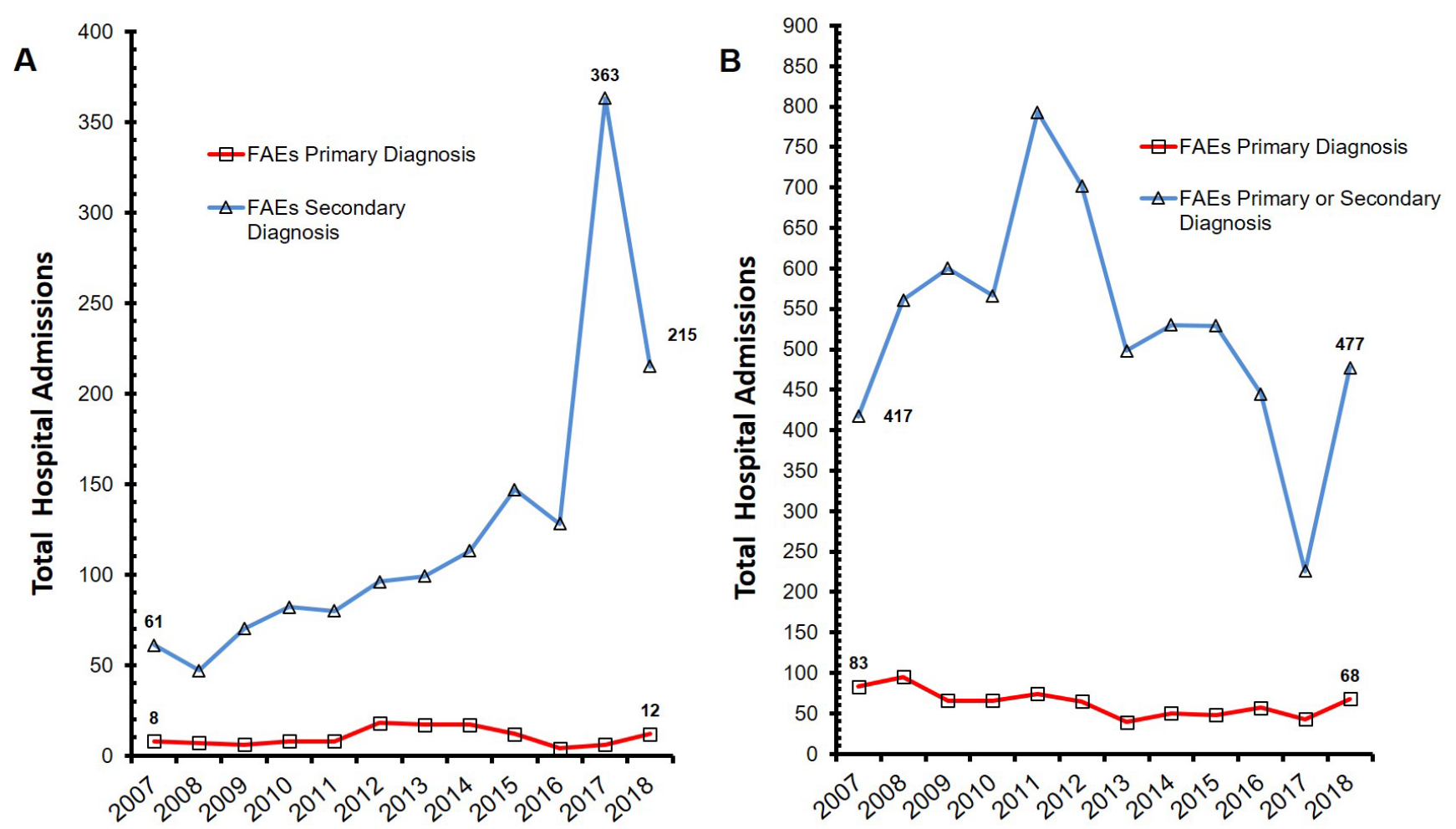

Figure 23. UK hospital Finished Admission Episodes (FAEs) with i) a primary diagnosis \& ii) a primary or secondary diagnosis of A) Scurvy, and B) Rickets, May 2007 - April 2008 to May 2018 - April 2019. Data from: NHS Digital: https://digital.nhs.uk/data-andinformation/find-data-and-publications/supplementary-information/2019-supplementary-information-files/victorian-diseases---hospitaladmissions.

gradient. In a high income country with an advanced economy and health care system, the existence of malnutrition and dietary related disease associated with poverty has to be considered a significant failure of public health policy.

\section{Food insecurity and overweight and obesity}

The relationship between food insecurity and undernutrition seems intuitively plausible. Paradoxically, food insecurity is also associated with obesity and weight gain. Evidence from the USA has long demonstrated an association between insecure access to food and obesity and weight gain, particularly in women with children (e.g. 67-70). There is also a growing literature demonstrating this relationship in American children, both cross-sectionally and longitudinally ${ }^{86,87}$. In the absence of a longitudinal measure of food insecurity, it is not possible to directly examine the relationship between food insecurity and overweight and obesity status in the UK. However, existing data shows a clear relationship between socio-economic status and weight. Taking children as an example, Figure 25 and Figure 26 show the prevalence of overweight and obesity by income deciles in English children aged 4-5 and 10-11, respectively, between 2006 and 2018. Overweight and obesity rates in 4-5 year olds in England have been fairly consistent across time aside from some fluctuations about the median and a reduction in the least deprived. However, there is a clear gradient of incidence between the income deciles with greater prevalence in poorer children. The contrast across income groups in 10-11 year olds is even starker. Overweight and obesity prevalence in the most deprived deciles has been increasing at a fairly steady rate since 2006. Conversely, rates in the least deprived children show a levelling off and reduction in prevalence from 2011.

It is important to consider that the relationship between nutrition and weight gain and obesity is complex and influenced by multiple factors beyond food availability and access. Further, the potential determinants of the relationship between food insecurity and weight are not fully elucidated ${ }^{70}$. Proposed mediators include the tendency for the cheapest food to be the most energy dense, least nutritious and especially palatable to children $^{63,88}$. Food insecurity is also likely to cause stress and anxiety which are known to impact food choice, eating patterns and energy metabolism ${ }^{89}$. Whilst there is evidence of a link between weight and food insecurity, overweight and obesity status cannot be employed to estimate food insecurity prevalence. Measures of household food insecurity capture data during a specific period of time at a household level, whilst nutritional outcomes, such as weight, are the results of the long-term nutritional experience of the individual ${ }^{90}$. However, longitudinal data shows a clear pattern of inequality in overweight and obesity prevalence in the UK children; 


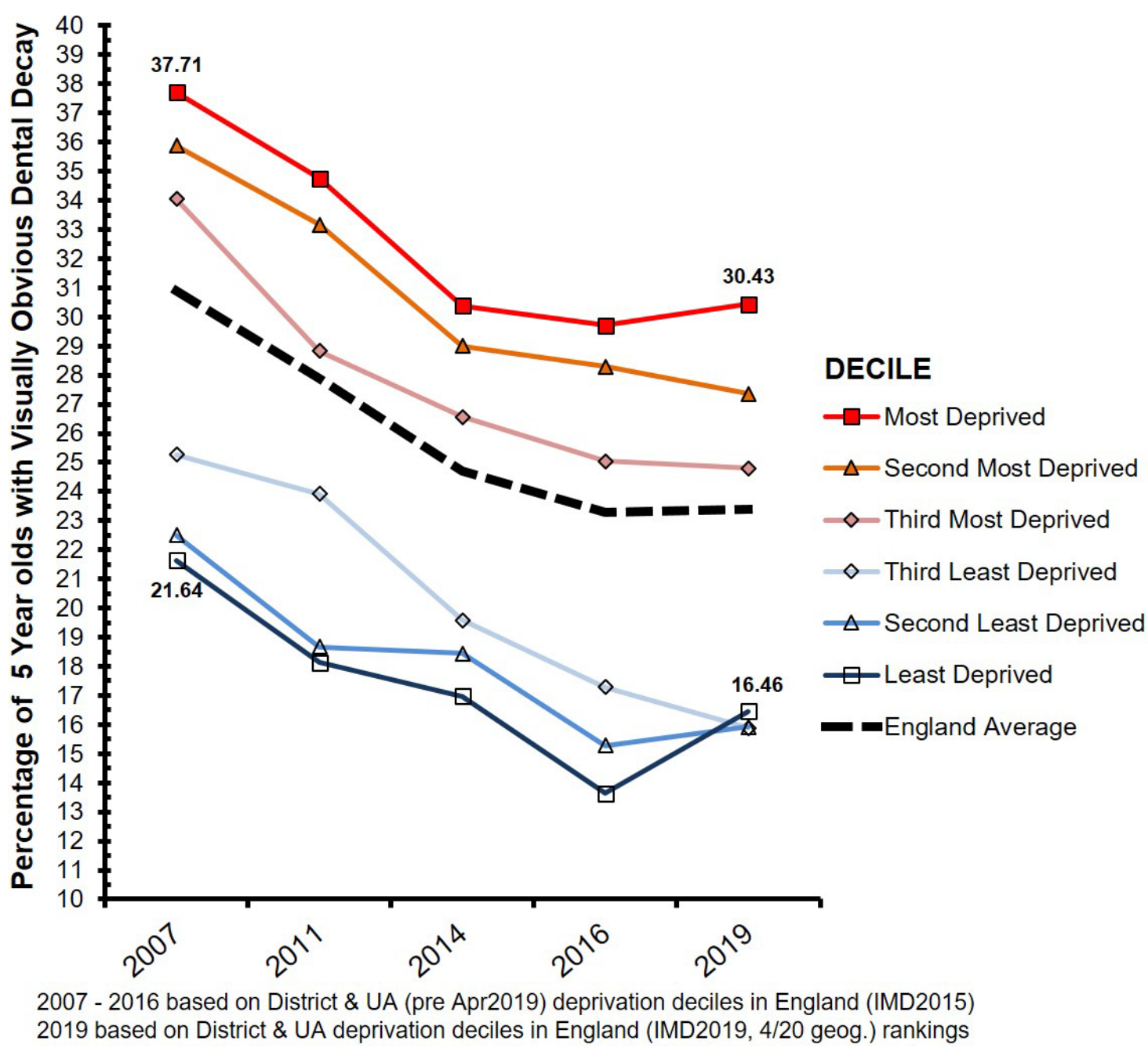

Figure 24. Percentage of 5 year olds with experience of visually obvious dental decay in England by Deprivation Decile 2007 - 2019. Data from: Public Health England Public Health Profiles: https://fingertips.phe.org.uk/.

this is also evident in the UK adult population ${ }^{91}$. Understanding the causes of these inequalities requires the careful measurement of food insecurity at the individual level in adults and children to permit the development of targeted public health interventions. The impact of the pandemic is likely to have heightened the need for action considering recent evidence that unhealthy food consumption increased, and fruit and vegetable intake decreased, during the first UK lockdown of 2020; this effect was heightened amongst poorer children $^{92}$.

\section{Discussion}

Prior to the inclusion of the food insecurity module in the 2019/20 FRS, routine collection of large scale data on the prevalence of food insecurity in the UK was severely limited. The 2003-2005 FSA Low Income Diet and Nutrition Survey and the Adult Food Security Module of the Food and You Survey, introduced in 2016, are the only other standardised national surveys that have measured the prevalence of food insecurity at a UK population level. As a consequence, quantitative estimates of food insecurity since 2005 have largely relied on a patchwork of data collected by third sector organisations, alongside cohort studies of maternal populations ${ }^{18,93}$. This evidence, combined with the rich and detailed qualitative first-hand accounts of those living under the spectre of food insecurity, have provided an invaluable, but crucially incomplete, insight into the prevalence of food insecurity in the UK. 


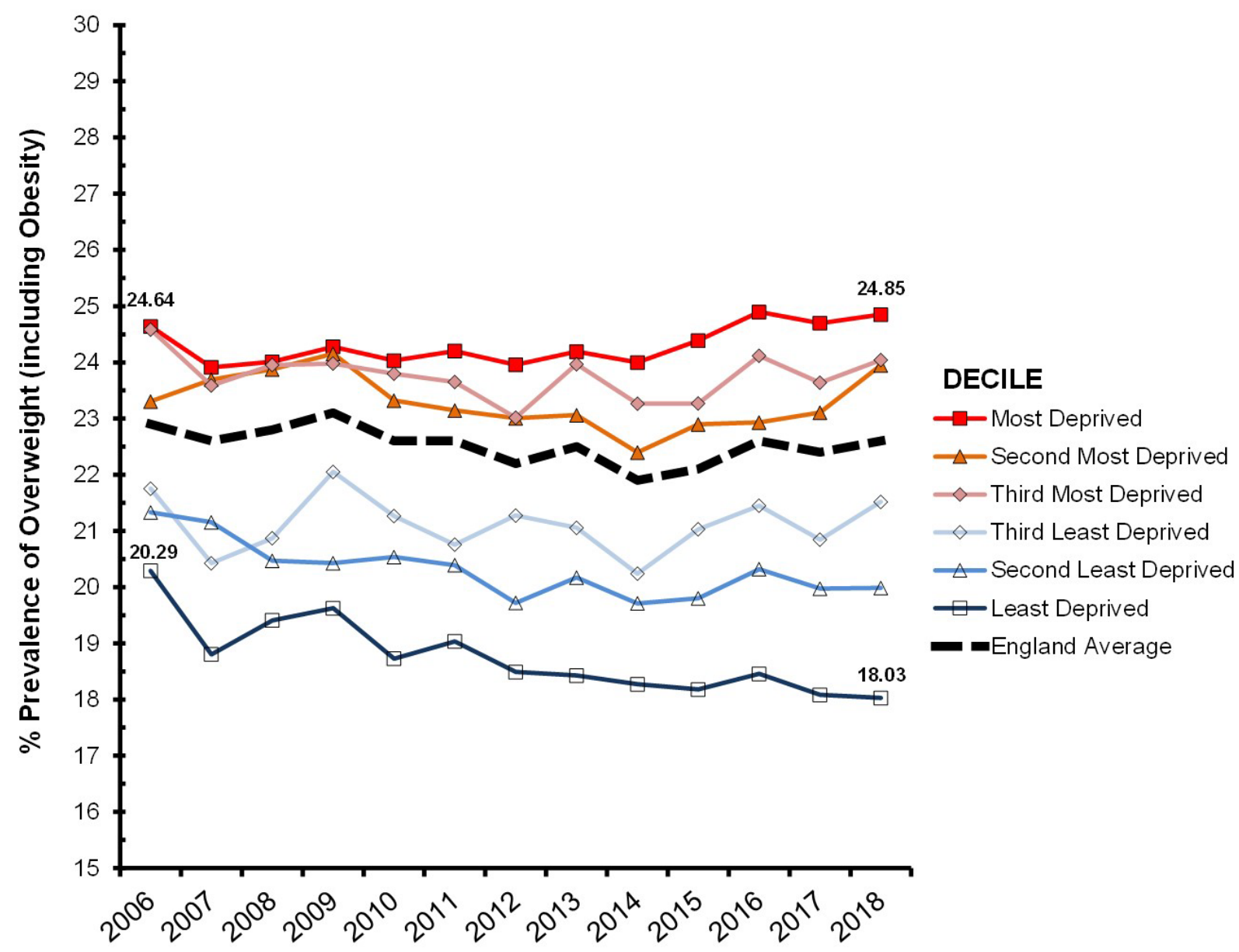

Based on District \& UA deprivation deciles in England (IMD2019, 4/20 geog.) rankings

Figure 25. Prevalence of overweight (inc. obesity) in 4-5 year olds in England by Deprivation Deciles 2006 - 2018 (to aid clarity, only 3rd highest and lowest deciles shown). Data from: Public Health England Public Health Profiles: https://fingertips.phe.org.uk/.

Taking the most frequently adopted data source of food bank usage exemplifies this. The experience of food bank users can provide an important insight into some of the drivers, and therefore potential proxy indicators, of food insecurity. Food bank data is also uniquely useful as it has been reported longitudinally since food bank networks and usage started to increase circa 2005. Despite issues with the granularity of food bank statistics - e.g. identifying unique users - the data certainly suggests that the prevalence of food insecurity in the UK has increased significantly since 2005 . This increase coincided with wider economic factors, such as austerity measures and social security reform. Indeed, despite Lord Freud's assertion in the 2013 House of Lords' food bank debate that 'food from a food bank - the supply - is a free good, and by definition there is an almost infinite demand' ${ }^{94}$, UK social security policies such as the UC rollout, benefit sanctions, and disability benefit reform, have been confirmed as drivers of food bank usage ${ }^{19}$.

However, food bank data can give only an incomplete measure of the prevalence of food insecurity. Measurement scales of food insecurity commonly differentiate between the severities of food insecurity faced. For example, the UN Food and Agricultural Organisation's Food Insecurity Experience Scale (FIES) rates the experiential severity of food insecurity on a spectrum from mild - uncertainty about one's ability to obtain food, to moderate - compromising on the quality/variety of food and reducing quantity of food eaten, through to severe food insecurity - no food for a day or more ${ }^{95}$. Those that access food bank provision are likely to fall towards the severe end of the scale - a significant proportion of food bank users report 


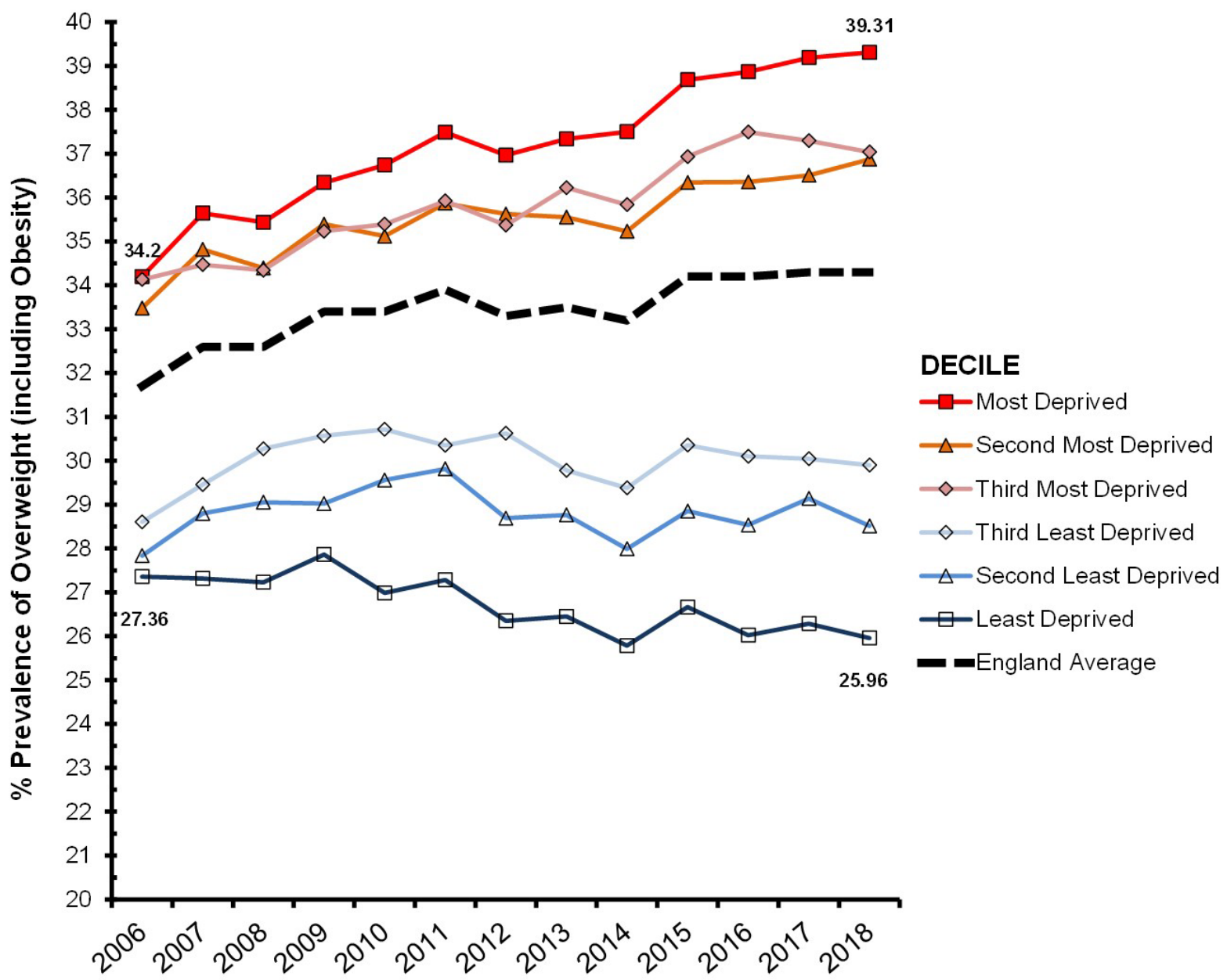

Based on District \& UA deprivation deciles in England (IMD2019, 4/20 geog.) rankings

Figure 26. Prevalence of overweight (inc. obesity) in 10-11 year olds in England by Deprivation Deciles 2006 - 2018 (to aid clarity, only 3rd highest and lowest deciles shown). Data from: Public Health England Public Health Profiles: https://fingertips.phe.org.uk/.

being destitute ${ }^{19}$ - and therefore can be considered a nonrepresentative subset of the food insecure population ${ }^{22}$. Worry over capacity to reliably obtain food and compromising on the quality of food consumed are associated with profound negative effects on mental and physical health ${ }^{10-12}$. It is essential that the number of individuals and households experiencing this mild to moderate level of food insecurity are accounted for in any measure of food insecurity prevalence. It is also evident that the majority of those in need may not access food bank provision ${ }^{23}$ and will therefore remain unacknowledged.

Can wider economic indicators be used to approximate the potential prevalence of food insecurity across the full experiential scale of severity? Poverty and associated economic markers can at least be considered indicative of a landscape in which there is an increased risk of food insecurity for many in a population. The Joseph Rowntree Foundation considers trends in poverty to be driven primarily by four factors: earnings, employment rate, housing costs, and benefits ${ }^{33}$. Since 2005, there has been a lack of a sustained period during which all four drivers were positively trending in a direction that would protect living standards as the UK faced a period of relatively poor growth by historical standards.

Significant economic shocks in the form of the recession, Brexit and the COVID-19 pandemic profoundly negatively affected the economic landscape in the UK. However, the impact of these economic shocks and the poor growth and stagnation shown in many economic markers have not been equitably distributed across the population. 
Increases in living standards have been particularly stagnant amongst the poorest households with those in the lowest 10th percentile seeing little increase in income for over eight years, largely as a result of a fall in the real value of working-age benefits and tax credits offsetting employment gains. This inequity is mirrored in direct measures of poverty. Despite a fairly stable overall population poverty rate of $\sim 22 \%$ since 2005 , relative child poverty has been rising since 2011 . This apparent stability also masks a deepening of poverty for those in the lowest 10th percentile of income living below the poverty line. Nevertheless, overall, poverty trends only give a general impression of the economic position of a proportion of the population, and without a longitudinal direct measure of food insecurity it is difficult to determine the prevalence of and changes in food insecurity itself. There is no agreed level of poverty that can be used as a yardstick by which to classify households as vulnerable to, or likely to be experiencing, food insecurity. Further, data from the US shows that poverty and food insecurity are not always corollary ${ }^{9}$. However, a high proportion of households most at risk of food insecurity are likely located at the extreme end of the poverty distribution, including within this $10 \%$ percentile that have experienced a worsening economic position over recent years.

One would expect the prevalence or risk of food insecurity to fall as UK employment rates have increased. However, in-work poverty and a growing number of, particularly young, adults working in precarious employment has risen since the recession. Significant changes in housing tenure and housing costs have also disproportionately affected low income households, and younger adults in particular. Poorer households spend more of their income on housing and this disparity has been increasing since $2007 / 08^{29}$. A scarcity of social housing stock and rising cost of homeownership have shifted housing tenure away from relatively secure social housing and towards private rental. Living in less secure, privately rented accommodation now outstrips homeownership and socially rented accommodation combined in adults under 40 living in relative poverty ${ }^{57}$. Whilst private rental accommodation is more expensive, the cost of social housing has also increased resulting in a growing proportion of poorer households spending over a third of their income on housing.

Poorer households typically also spend a greater proportion of their total income on food and have subsequently been disproportionately affected by fluctuations in food costs over recent years. Income stagnation in the lowest income households in the wake of the recession coincided with rising food costs to reduce the affordability of food. This is likely to have had direct consequences for the dietary choices for poorer households. Reductions in quantity and quality of food are both central to definitions of food insecurity. Since food is often the only flexible item in a household budget, fluctuations in the cost of food, increased housing costs and reduced income will likely have reduced the amount and/or quality of food the poorest households could afford. Beyond local level analyses (see 96), it is not possible to establish a causal link between food affordability, diet quality and food insecurity due the paucity of food insecurity data. Data on overweight and obesity levels from the poorest households and re-emergence of nutrition-related diseases is certainly indicative of a reduced quality of diet. Similarly, a worrying growth in malnutrition in younger population groups also suggests a reduction in the quantity and quality of diet. However, in the absence of longitudinal food insecurity data collection, it is not possible to establish what part, if any, food insecurity plays in these trends. What is clear, however, is that socio-economic inequity plays a key role in diet quality and nutrition-related outcomes.

Changes in the UK economic landscape during and after the recession, accompanied by rising living costs, have put extra strain on low income households, potentially increasing the likelihood of poverty and food insecurity. However, these events have been exacerbated for many households by the welfare reform policies since 2010. Evidence suggests that welfare reforms and austerity measures are a prime proxy indicator for increasing food insecurity since 2005. In 2018, the Equality and Human Rights Commission concluded that UK tax and welfare reforms since 2010 have disproportionately impacted the poorest households ${ }^{97}$. The retraction of the welfare state under the banner of 'austerity' effectively shrank the social security safety net, increasing poverty among low income households. The effects of welfare diversification, public spending cuts, benefit conditionality and benefit freezes, and a reduced real value of benefits have combined to reduce the incomes of those households already below and close to the poverty line - the unemployed or unable to work, the underemployed, those working on low paid or precarious contracts, those requiring disability support, households containing children - at a time of existing economic hardship, increasing vulnerability to food insecurity in those known to be disproportionately at risk $^{2}$. There is certainly evidence to indicate that social security and welfare policies have directly increased severe food insecurity, as represented by food bank usage ${ }^{98}$. It is not known what effects these profound social policy changes have had on the prevalence of mild to moderate food insecurity; as we have seen these are often hidden and harder to quantify without a direct measure of food insecurity. Reduced social care provision during austerity may have contributed to a growing level of malnutrition in older adults. However, the determinants of malnutrition are multiple, complex and difficult to disentangle. The inaugural food insecurity module of the 2019/20 FRS suggests comparatively low household levels of food insecurity in those over 65 years. However, overall food insecurity prevalence varied considerably as a function of household composition and tenure, geographical location, disability status, education level, ethnicity and income, indicating an as yet unexplored interaction of social and economic determinants.

Ultimately, the use of proxy indicators to estimate the longitudinal prevalence of food insecurity is necessitated by a lack of formalised measurement. It is clear that food bank data, wider economic and social welfare provision markers, and nutrition-related health outcomes are not sufficient to give any comprehensive or clear indication of food security prevalence. However, it is possible to speculate that food insecurity has 
increased since the early 21 st century, at least towards the most severe end of the food insecurity scale as indexed by food bank data. It is also clear that a combination of economic and socio-political factors over the last 15 to 20 years, particularly post-recession, have created conditions in which the risk of food insecurity is likely to have increased for the poorest and most vulnerable UK households. The available data also strikingly illustrates the difficulty of accounting for the full spectrum of food insecurity experience in the absence of a direct measure. It is particularly difficult to account for and measure the experience of mild to moderate food insecurity since many proxy markers and outcomes tend to be more closely associated with severe food insecurity. Food bank and incomebased data give very little insight into the number of households or individuals that may regularly face worry or anxiety about securing sufficient quantities of food.

The societal impacts of food insecurity are too great to rely on approximation. Proxy data is not sufficiently robust or defined to be utilised to lever policy change to protect those vulnerable to or facing food insecurity. The inclusion of the USDA Food Security Measurement Module in the FRS ensures the standardised measurement and monitoring of food insecurity in the UK going forward. This will permit a clear measurement of the prevalence and those at risk of food insecurity, how it changes longitudinally and in relation to interventions and national policy, and the role it plays in negative social and health outcomes.

The adoption of the USDA Food Security Measurement Module should not be considered a perfect solution to a lack of food insecurity data in the UK. Firstly, the timeframe adopted only accounts for the last 30 days, rather than the commonly administered 12 months, which has been shown to underestimate food insecurity levels ${ }^{99}$. Second, this measure only accounts for food insecurity at the household level without specific reference to potential variability in food insecurity within households. For example, the items in the measure refer only to adults meaning no accurate indication of the level of food insecurity in children will be available. Moreover, the collection of quantitative data does not always naturally lead to action; there needs to be political will and public pressure to enact necessary interventions. It can also be argued that there is already sufficient evidence to show food insecurity in the UK is a problem for a sizable proportion of the population. Therefore, the focus of efforts should be to target resources on addressing the issue rather than delay response to permit standardised measurement. Further, targeting food insecurity in isolation may result in food-based only solutions (e.g. food charity, redistribution of surplus food) and neglect of the wider overarching societal and economic problems, particularly the government's response to alleviate poverty and the causes of poverty.

\section{Conclusion}

Our analysis of proxy measures suggests an increase in food insecurity since 2005 in the UK, particularly in levels of severe food insecurity. Proxy measures are, however, inadequate to robustly assess the character and prevalence of food insecurity. The recent inclusion of food insecurity measurement in the FRS is welcome and should be continued. However, the historical absence of longitudinal data on UK household food insecurity means it is impossible to accurately ascertain the extent to which food insecurity has increased since 2005 and particularly since the introduction of 'austerity' in 2010. The COVID-19 pandemic has exacerbated food insecurity among vulnerable groups and led to newly food insecure populations ${ }^{100}$, suggesting that changes to government social policy may now be needed urgently to reduce food insecurity among the UK population.

\section{Data availability \\ Underlying data}

Sources of all data underlying the results are given as part of the article and no additional source data are required.

\section{Acknowledgements}

The authors would like to acknowledge the support provided through the Rapid Evidence Synthesis Training (REST) programme. REST was organised and delivered through a collaboration between the University of Leeds, The University of Newcastle and the N8 AgriFood Programme and supported by Research England QR-SPF funds from The University of Leeds and University of York. We gratefully thank and acknowledge those researchers and authors whose work we summarise in this review. The authors are also grateful for the time and patience of Prof. Mark Reed (Newcastle University) in kindly reviewing the initial draft of the manuscript. Dr David Webster (University of Glasgow) is also gratefully acknowledged for his time providing feedback on sections which summarised his work on benefit sanction data.
1. Fuller E, et al.: The Food and Your Survey Wave 5. Food Standards Agency London. 2019.

2. Department for Work and Pensions: Family Resources Survey: financial year 2019 to 2020. UK Government, Editor. Reference Source
3. Armstrong, B, King, L, Clifford R, et al.: Food and You 2: Wave 1 Key Findings. Food Standards Agency. F.S. Agency, Editor. 2021. Reference Source

4. Koltai J, Toffolutti V, McKee M, et al.: Prevalence and changes in food-related hardships by socioeconomic and demographic groups during the COVID-19 
pandemic in the UK: A longitudinal panel study. Lancet Reg Health Eur. 2021; 6: 100125.

Publisher Full Text

5. Lambie-Mumford, H: Hungry Britain: The rise of food charity. Bristol: Policy Press. 2017.

Publisher Full Text

6. Davis O, Geiger BB: Did Food Insecurity rise across Europe after the 2008 Crisis? An analysis across welfare regimes. Soc Policy Soc. 2017; 16(3): 343-360.

Publisher Full Text

7. Loopstra R, Reeves A, Tarasuk V: The rise of hunger among low-income households: an analysis of the risks of food insecurity between 2004 and 2016 in a population-based study of UK adults. J Epidemiol Community Health 2019; 73(7): 668-673.

PubMed Abstract | Publisher Full Text

8. Pybus K, Power M, Pickett K: 'We are constantly overdrawn, despite not spending money on anything other than bills and food': a mixed-methods, participatory study of food and food insecurity in the context of income inequality. J Poverty Soc Justice. 2020; 29(1): 21-22. Publisher Full Text

9. Gundersen C, Kreider B, Pepper J: The Economics of Food Insecurity in the United States. Appl Econ Perspect Policy. 2011; 33(3): 281-303. Publisher Full Text

10. Stuff JE, Casey PH, Szeto KL, et al.: Household Food Insecurity Is Associated with Adult Health Status. J Nutr. 2004; 134(9): 2330-2335. PubMed Abstract | Publisher Full Text

11. Tarasuk V, Mitchell A, McLaren L, et al.: Chronic physical and mental health conditions among adults may increase vulnerability to household food insecurity. J Nutr. 2013; 143(11): 1785-93. PubMed Abstract | Publisher Full Text

12. Power $\mathrm{M}$, Uphoff $\mathrm{E}$, Kelly $\mathrm{B}$, et al.: Food insecurity and mental health: an analysis of routine primary care data of pregnant women in the Born in Bradford cohort. J Epidemiol Community Health. 2017; 71(4): 324-328. PubMed Abstract | Publisher Full Text

13. Power MS, Small N, Doherty B, et al.: Is food insecurity associated with maternal health among UK ethnic groups? An exploration of women in the BiB cohort. Eur J Public Health. 2018; 28(4): 661-663. PubMed Abstract | Publisher Full Text

14. Adams EJ, Grummer-Strawn L, Chavez G: Food Insecurity Is Associated with Increased Risk of Obesity in California Women. J Nutr. 2003; 133(4): 1070-1074.

PubMed Abstract | Publisher Full Text

15. Eicher-Miller HA, Zhao Y: Evidence for the age-specific relationship of food insecurity and key dietary outcomes among US children and adolescents. Nutr Res Rev. 2018; 31(1): 98-113. PubMed Abstract | Publisher Full Text

16. Fram MS, Ritchie LD, Rosen N, et al.: Child Experience of Food Insecurity Is Associated with Child Diet and Physical Activity. J Nutr. 2015; 145(3): 499-504.

PubMed Abstract | Publisher Full Text

17. Jyoti DF, Frongillo EA, Jones SJ: Food Insecurity Affects School Children's Academic Performance, Weight Gain, and Social Skills. J Nutr. 2005; 135(12): 2831-2839.

PubMed Abstract | Publisher Full Text

18. Power, M, Uphoff EP, Stewart-Knox B, et al.: Food insecurity and sociodemographic characteristics in two UK ethnic groups: an analysis of women in the Born in Bradford cohort. J Public Health (Oxf). 2017; 40(1): 32-40. PubMed Abstract | Publisher Full Text

19. Sosenko F, Littlewood M, Bramley G, et al:: State of Hunger: A study of poverty and food insecurity in the UK. The Trussell Trust. 2019 Reference Source

20. Loopstra R, Goodwin S, Goldberg B, et al.: A survey of food banks operating independently of the Trussell Trust food bank network. 2019. Reference Source

21. Tyler G: Briefing Paper: Food banks in the UK. House of Commons Library, 2021

Reference Source

22. Loopstra R, Tarasuk V: Food Bank Usage Is a Poor Indicator of Food Insecurity: Insights from Canada. Soc Policy Soc. 2015; 14(3): 443-455. Publisher Full Text

23. MacLeod MA, Curl A, Kearns A: Understanding the prevalence and drivers of food bank use: evidence from deprived communities in Glasgow. Soc Policy Soc. 2019; 18(1): 67-86. Publisher Full Text

24. ONS: Gross Domestic Product: q-on-q4 growth rate CVM SA \%. Office of National Statistics, 2020.

Reference Source

25. ONS: Labour market overview, UK: January 2021. Estimates of employment, unemployment, economic inactivity and other employment-related statistics for the UK. Office for National Statistics, 2021. Reference Source
26. Bourquin $P$, Joyce R, Keiller AN: Living standards, poverty and inequality in the UK: 2020. The Institute for Fiscal Studies, 2020.

Reference Source

27. Hood A, Waters T: Living standards, poverty and inequality in the UK: 201718 to 2021-22. Institue of Fiscal Studies: London. 2017. Reference Source

28. Francis-Devine B: BRIEFING PAPER: Poverty in the UK: statistics. House of Commons Library: London. 2020. Reference Source

29. Bourquin $\mathrm{P}$, Cribb J, Waters $\mathrm{T}$, et al.: Why has in-work poverty risen in Britain? Institute of Fiscal Studies Working Paper. 2019. Reference Source

30. Cribb J, Hood A, Joyce R, et al.: Living Standards, Poverty and Inequality in the UK: 2017. Institute for Fiscal Studies: London. 2017. Reference Source

31. Bourquin P, Cribb J, Waters $T$, et al.: Living Standards, Poverty and Inequality in the UK: 2019. Institute for Fiscal Studies: London. 2019. Reference Source

32. Belfield C, Cribb J, Hood A, et al.: Living Standards, Poverty and Inequality in the UK: 2015. Institute for Fiscal Studies: London. 2015 Reference Source

33. Joseph Rowntree Foundation: UK Poverty 2019/2020. The Leading Independent Report. Joseph Rowntree Foundation: York, 2020. Reference Source

34. ONS: EMP17: People in employment on zero hours contracts. ONS, Editor. Office for National Statistics: London. 2020. Reference Source

35. Department for Business Energy and UK Industrial Strategy: Guidance: Zero hours contracts: guidance for employers. BEIS, Editor. London, 2015. Reference Source

36. Bender KA, Theodossiou I: The Unintended Consequences of Flexicurity: The Health Consequences of Flexible Employment. 2018; 64(4): 777-799. Publisher Full Text

37. Equality and Human Right Commission: How coronavirus has affected equality and human rights. In: Is Britain Fairer? Report series. London, 2020. Reference Source

38. Joseph Rowntree Foundation: UK POVERTY 2020/21: The Leading Independent Report. Joseph Rowntree Foundation, 2021. Reference Source

39. HM Revenue and Customs and Department of Work and Pensions: Child Tax Credit and Universal Credit claimants: Statistics related to the policy to provide support for a maximum of two children. HMRC Press Office London. 2020.

Reference Sourc

40. National Audit Office: Benefit sanctions. 2016. Reference Source

41. Oakley M: Independent review of the operation of Jobseeker's Allowance sanctions validated by the Jobseekers Act 2013. 2014. Reference Source

42. Webster D: BRIEFING: The DWP's JSA/ESA Sanctions Statistics Release, 17 August 2016 - Supplement: Explaining the rise and fall of JSA and ESA sanctions 2010-16. 2016.

43. Department for Work and Pensions: Official Statistics: Benefit sanctions statistics to January 2020. UK Government. 2020. Reference Source

44. Webster D: BRIEFING: Benefit Sanctions Statistics. 2020 Reference Source

45. Webster D: BRIEFING: Benefit Sanctions Statistics: JSA, ESA and Universal Credit February 2017. 2017.

Reference Source

46. Webster D: BRIEFING: Benefit Sanctions Statistics November 2018. 2018.

47. Schwartz N, Buliung R, Wilson K: Disability and food access and insecurity: A scoping review of the literature. Health Place. 2019; 57: 107-121. PubMed Abstract | Publisher Full Text

48. Geiger BB: Benefits conditionality for disabled people: stylised facts from a review of international evidence and practice. J Poverty Soc Justice. 2017; 25(2): 107-128. Publisher Full Text

49. Webster D: BRIEFING: Benefit sanctions statistics February 2016. 2016

50. Work and Pension Committee: House of Commons Select Committee: Benefit Sanctions. UK Parliamentary Report, 2018.

51. Webster D: BRIEFING: Benefit Sanctions Statistics. 2019. Reference Source

52. The Trussel Trust: Lift the burden: Tackling the government debts facing people at food banks. 2020 Reference Source

53. Webster D: BRIEFING: Benefit Sanction Statistics February 2021. 2021 Reference Source

54. Webster D: BRIEFING: Benefit Sanctions Statistics. 2021 
55. Joyce R, Mitchell M, Keiller AN: The cost of housing for low-income renters. Institute for Fiscal Studies: London. 2017. Publisher Full Text

56. Bramley G: Housing supply requirements across Great Britain: for low-income households and homeless people. Crisis and National Housing Federation: London. 2018.

Reference Source

57. Bailey N: Poverty and the re-growth of private renting in the UK, 1994-2018. PLoS One. 2020; 15(2): e0228273.

PubMed Abstract | Publisher Full Text | Free Full Text

58. Turrell G, Hewitt B, Patterson C, et al:: Socioeconomic differences in food purchasing behaviour and suggested implications for diet-related health promotion. J Hum Nutr Diet. 2002; 15(5): 355-364. PubMed Abstract | Publisher Full Text

59. Department for Environment Food \& Rural Affairs: Food Statistics in your pocket: Prices and expenditure. DEFRA. 2020. Reference Source

60. Lee A, Mhurchu CN, Sacks G, et al.: Monitoring the price and affordability of foods and diets globally. Obes Rev. 2013; 14 Suppl 1(S1): 82-95. PubMed Abstract | Publisher Full Text

61. Glanz K, Basil M, Maibach E, et al.: Why Americans Eat What They Do: Taste, Nutrition, Cost, Convenience, and Weight Control Concerns as Influences on Food Consumption. J Am Diet Assoc. 1998; 98(10): 1118-1126. PubMed Abstract | Publisher Full Text

62. Hanson KL, Connor LM: Food insecurity and dietary quality in US adults and children: a systematic review. Am J Clin Nutr. 2014; 100(2): 684-692. PubMed Abstract | Publisher Full Text

63. Darmon N, Briend A, Drewnowski A: Energy-dense diets are associated with lower diet costs: a community study of French adults. Public Health Nutr. 2004; 7(1): 21-7.

PubMed Abstract | Publisher Full Text

64. Drewnowski A, Specter SE: Poverty and obesity: the role of energy density and energy costs. Am J Clin Nutr. 2004; 79(1): 6-16. PubMed Abstract | Publisher Full Text

65. Jones NRV, Conklin AI, Suhrcke M: The Growing Price Gap between More and Less Healthy Foods: Analysis of a Novel Longitudinal UK Dataset. PLOS One. 2014; 9(10): e109343.

PubMed Abstract | Publisher Full Text | Free Full Text

66. Scott C, Sutherland J, Taylor A: Affordability of the UK's Eatwell Guide. The Food Foundation. 2018. Reference Source

67. Morales ME, Berkowitz SA: The Relationship Between Food Insecurity, Dietary Patterns, and Obesity. Curr Nutr Rep. 2016; 5(1): 54-60. PubMed Abstract | Publisher Full Text | Free Full Text

68. Dhurandhar EJ: The food-insecurity obesity paradox: A resource scarcity hypothesis. Physiol Behav. 2016; 162: 88-92. PubMed Abstract | Publisher Full Text | Free Full Text

69. Franklin B, Jones A, Love D, et al.: Exploring Mediators of Food Insecurity and Obesity: A Review of Recent Literature. J Community Health. 2012; 37(1): 253-264.

PubMed Abstract | Publisher Full Text | Free Full Text

70. Brown AGM, Esposito LE, Fisher RA, et al.: Food insecurity and obesity: research gaps, opportunities, and challenges. Trans/ Behav Med. 2019; 9(5): 980-987. PubMed Abstract | Publisher Full Text | Free Full Text

71. UK Stakeholders for Sustainable Development (Development USfS): Measurin up. How the UK is performing on the UN Sustainable Development Goals. UKSSD. 2018. Reference Source

72. National Institute for Health and Care Excellence: Nutrition support for adults: oral nutrition support, enteral tube feeding and parenteral nutrition. NICE. 2017

Reference Source

73. Russell CA, Elia M: Nutrition Screening Survey in the UK and Republic of Ireland in 2011. The British Association for Parenteral and Enteral Nutrition. 2012.

Reference Source

74. WHO: ICD-10 : international statistical classification of diseases and related health problems : tenth revision. World Health Organization: Geneva. 2004. Reference Source

75. Elia M: The cost of malnutrition in England and potential cost savings from nutritional interventions. Malnutrition Action Group of BAPEN and National Institute for Health Research Southampton Biomedical Research Centre. 2015. Reference Source

76. Association for Public Service Excellence: Meals on Wheels Survey 2018. National Association of Care Catering. 2018.

Reference Source

77. Fávaro-Moreira NC, Krausch-Hofmann S, Matthys C, et al:: Risk Factors for Malnutrition in Older Adults: A Systematic Review of the Literature Based on Longitudinal Data. Adv Nutr. 2016; 7(3): 507-22. PubMed Abstract | Publisher Full Text | Free Full Tex
78. Boulos C, Salameh P, Barberger-Gateau P: Social isolation and risk for malnutrition among older people. Geriatr Gerontol Int. 2017; 17(2): 286-294. PubMed Abstract | Publisher Full Text

79. Tsofliou F, Grammatikopoulou MG, Lumley R, et al.: Effects of lunch club attendance on the dietary intake of older adults in the UK: A pilot crosssectional study. Nutr Health. 2020; 26(3): 209-214. PubMed Abstract | Publisher Full Text | Free Full Text

80. Harris T, Hodge L, Phillips D: English local government funding: trends and challenges in $\mathbf{2 0 1 9}$ and beyond. Institute for Fiscal Studies Report. 2019. Reference Source

81. Crawford R, Stoye G, Zaranko B: What impact did cuts to social care spending have on hospitals? Institute for Fiscal Studies. 2020. Reference Source

82. National Audit Office: Local government finance in the pandemic. 2021. Reference Source

83. Macaninch E, Martyn K, Lima do Vale M: Exploring the implications of COVID-19 on widening health inequalities and the emergence of nutrition insecurity through the lens of organisations involved with the emergency food response. BMJ Nutr Prev Health 2020; 3(2): 374-382. PubMed Abstract | Publisher Full Text | Free Full Text

84. Calder PC, Jackson AA: Undernutrition, infection and immune function. Nutr Res Rev. 2000; 13(1): 3-29. PubMed Abstract | Publisher Full Tex

85. Middleton J: Why we should be concerned about the return of Victorian diseases. The Guardian. 2014 Reference Source

86. Dinour LM, Bergen D, Yeh MC: The food insecurity-obesity paradox: a review of the literature and the role food stamps may play. J Am Diet Assoc. 2007; 107(11): 1952-61. PubMed Abstract | Publisher Full Text

87. Eisenmann JC, Gundersen C, Lohman BJ, et al.: Is food insecurity related to overweight and obesity in children and adolescents? A summary of studies, 1995- 2009. Obes Rev 2011; 12(5): e73-e83. PubMed Abstract | Publisher Full Text

88. Daniel C: Economic constraints on taste formation and the true cost of healthy eating. Soc Sci Med. 2016; 148: 34-41. PubMed Abstract | Publisher Full Text | Free Full Text

89. Yau YHC, Potenza MN: Stress and eating behaviors. Minerva Endocrinol. 2013; 38(3): 255-267. PubMed Abstract | Free Full Text

90. The Food Foundation: Food Insecurity \& Obesity: Measurement is the missing link. 2018. Reference Source

91. Lifestyles Team NHS Digital: Health Survey for England 2018. NHS Digital: London. 2018. Reference Source

92. Dimbleby H: National food strategy: part one. 2020. Reference Source

93. Pilgrim A, Barker $M$, Jackson A, et al.: Does living in a food insecure household impact on the diets and body composition of young children? Findings from the Southampton Women's Survey. J Epidemiol Community Health. 2012; 66(6): e6.

PubMed Abstract | Publisher Full Text | Free Full Text

94. UK Parliament: Food: Food Banks. House of Lords debate, Editor. 2013. Reference Source

95. Ballard TJ, Kepple AW, Cafiero C: The Food Insecurity Experience Scale: Development of a Global Standard for Monitoring Hunger Worldwide. in Food and Agriculture Organization of the United Nations. Rome. 2013. Reference Source

96. Power M, Pybus KJ, Pickett KE, et al.: The reality is that on Universal Credit I cannot provide the recommended amount of fresh fruit and vegetables per day for my children": Moving from a behavioural to a systemic understanding of food practices [version 1; peer review: 2 approved]. Emerald Open Res. 2021; 3(3). Publisher Full Text

97. Equality and Human Rights Commission: Is Britain fairer? 2018. Reference Source

98. Loopstra R, Clair A, Fledderjohann J, et al.: Impact of Welfare Benefit Sanctioning on Food Insecurity: a Dynamic Cross-Area Study of Food Bank Usage in the UK. J Soc Policy. 2018; 47(3): 437-457. Publisher Full Text

99. Loopstra R: Food insecurity measurement on the Family Resources Survey in ENUF: Evidence and Network on UK Household Food Insecurity. 2019. Reference Source

100. Loopstra R: Vulnerability to food insecurity since the COVID-19 lockdown Preliminary report. Vulnerability to food insecurity since the COVID-19 lockdown Preliminary report. The Food Foundation: London. 2020. Reference Source 


\section{Open Peer Review}

\section{Current Peer Review Status:}

\section{Version 1}

Reviewer Report 02 December 2021

https://doi.org/10.21956/emeraldopenres.15401.r27836

(C) 2021 Yau A. This is an open access peer review report distributed under the terms of the Creative Commons Attribution License, which permits unrestricted use, distribution, and reproduction in any medium, provided the original work is properly cited.

\section{Amy Yau}

Population Health Innovation Lab, Department of Public Health, Environments \& Society, Faculty of Public Health \& Policy, London School of Hygiene \& Tropical Medicine, London, United Kingdom

This is a well-written and comprehensive review of potential indicators of household food insecurity that could be used to examine longitudinal trends in the UK, and an important contribution to the UK food insecurity literature. I have only a few suggestions that I hope will improve the paper.

In general, all the potential indicators of food insecurity were presented along with their strengths and weakness in a nuanced way, which provides the reader with a lot of information. However, I felt something that brought these strands together was missing - perhaps a figure that shows how the different indicators are linked and/or a table that summarises the strengths and limitations of using each indicator and the availability of these data for the UK currently, which are well-described in the text.

Minor comments:

In the second sentence of the introduction "The Family Resource Survey (FRS) for the financial year 2019 to 2020 (data released 2021) identified 8\% of UK households to be food insecure, with low household food insecurity (4\%) or very low household food security (4\%)." - Should this be this be low household food security (4\%)?

Figure 2 - the $x$ axis labels might be easier to read if you just use the years, then in the caption state that each year is represented by data from August to October.

Is the work clearly and accurately presented and does it cite the current literature? Yes

Is the study design appropriate and is the work technically sound?

Yes 
Are sufficient details of methods and analysis provided to allow replication by others? Yes

If applicable, is the statistical analysis and its interpretation appropriate?

Not applicable

Are all the source data underlying the results available to ensure full reproducibility?

Yes

Are the conclusions drawn adequately supported by the results?

Yes

Is the argument information presented in such a way that it can be understood by a nonacademic audience?

Yes

Does the piece present solutions to actual real world challenges?

Yes

Is real-world evidence provided to support any conclusions made?

Yes

Could any solutions being offered be effectively implemented in practice?

Yes

Competing Interests: No competing interests were disclosed.

Reviewer Expertise: dietary public health; social determinants of health

I confirm that I have read this submission and believe that I have an appropriate level of expertise to confirm that it is of an acceptable scientific standard. 